\title{
Surface Chemistry in Tribology
}

\author{
Andrew J. Gellman \\ Lord Professor of Chemical Engineering and Professor of Chemistry \\ Department of Chemical Engineering \\ Carnegie Mellon University \\ Pittsburgh, PA 15213, USA
}

and

Nicholas D. Spencer

Professor of Surface Science and Technology

Department of Materials

Swiss Federal Institute of Technology

ETH-Zentrum, CH-8092 Zürich, Switzerland

\section{Introduction}

In general, the twentieth century marked the first major incursion of chemists into the world of tribology. Driven partly by the need for improved lubricants for new machines developed in the first few decades of the century, and partly by new analytical capabilities, lubricant chemists and tribochemists were to become full partners in the science of tribology. In this review we cover a number of topics in surface chemistry in tribology, which serve both to illustrate some of the successes in tribochemical research over the past decades, and also to show that much work remains to be done before true, first-principles tribochemistry-based lubricant and tribopair design can begin.

\section{Boundary Lubrication and Oiliness Additives}

In an ideal world, lubricated sliding surfaces are separated by a stable fluid film of lubricant, which effectively lowers friction and prevents wear, holding the surfaces apart by virtue of its fluid-mechanical properties. The friction coefficient in such a hydrodynamically lubricated bearing is proportional to $\eta \mathrm{U} / \mathrm{W}$, where $\mathrm{U}$ is the relative sliding speed of the surfaces, $W$ the normal load supported by the bearing and $\eta$ the Newtonian viscosity[1]. At low sliding speeds (e.g upon startup) and/or higher forces, however, the friction coefficient varies in a more complex way (Figure 1) and at the lowest speeds and friction forces can be 2 orders of magnitude higher than under hydrodynamic lubrication conditions. This is the regime of "boundary lubrication", where fluid films have given way to thin layers that serve as the active lubricants, and the realm of pure engineering (hydrodynamic lubrication) has given 
way to the complex world of surface chemistry under confinement. Boundary lubrication is clearly of vital importance, since it is the mechanism in operation under the most extreme of tribological conditions. Understanding boundary lubrication, however, has been a challenge to tribochemists over the last century, with light appearing at the end of the tunnel only quite recently.

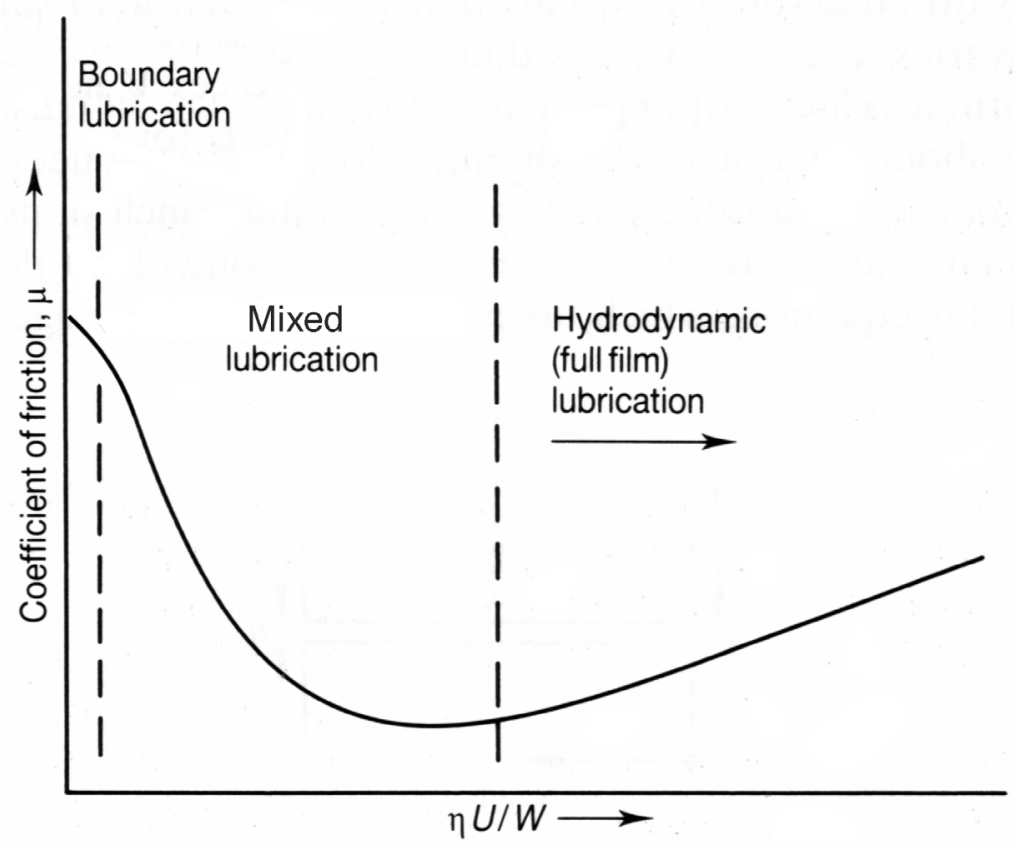

Figure 1. Stribeck curve: The variation in frictional drag (expressed as the coefficient of friction, $\mu)$ with the quantity $\eta U / W$ for a lubricated sliding bearing. After Hutchings [1].

\section{Monolayers, Multilayers and soaps}

It was noticed in the 1920s that certain lubricants possessed a quality designated "oiliness", which, independent of their viscosity, led to better lubrication at low sliding speeds[2-4]. Generally, these oily lubricants tended to be those of natural origin, such as castor oil, containing long-chain oxygenated organic compounds (esters and acids), which have surfactant properties, and are not usually present in their mineral oil counterparts. It was shown that these oxygenated molecules could, by themselves, reduce friction considerably between sliding surfaces, their effectiveness depending on their molecular weight[5] (Figure 2). Hardy developed a monolayer theory of boundary lubrication (Figure 3), whereby he postulated that, under boundary conditions, the sliding surfaces were held apart by adsorbed, oriented monolayers of polar molecules, which form a plane of low shear strength, thus lowering friction and affording protection of the surfaces. 


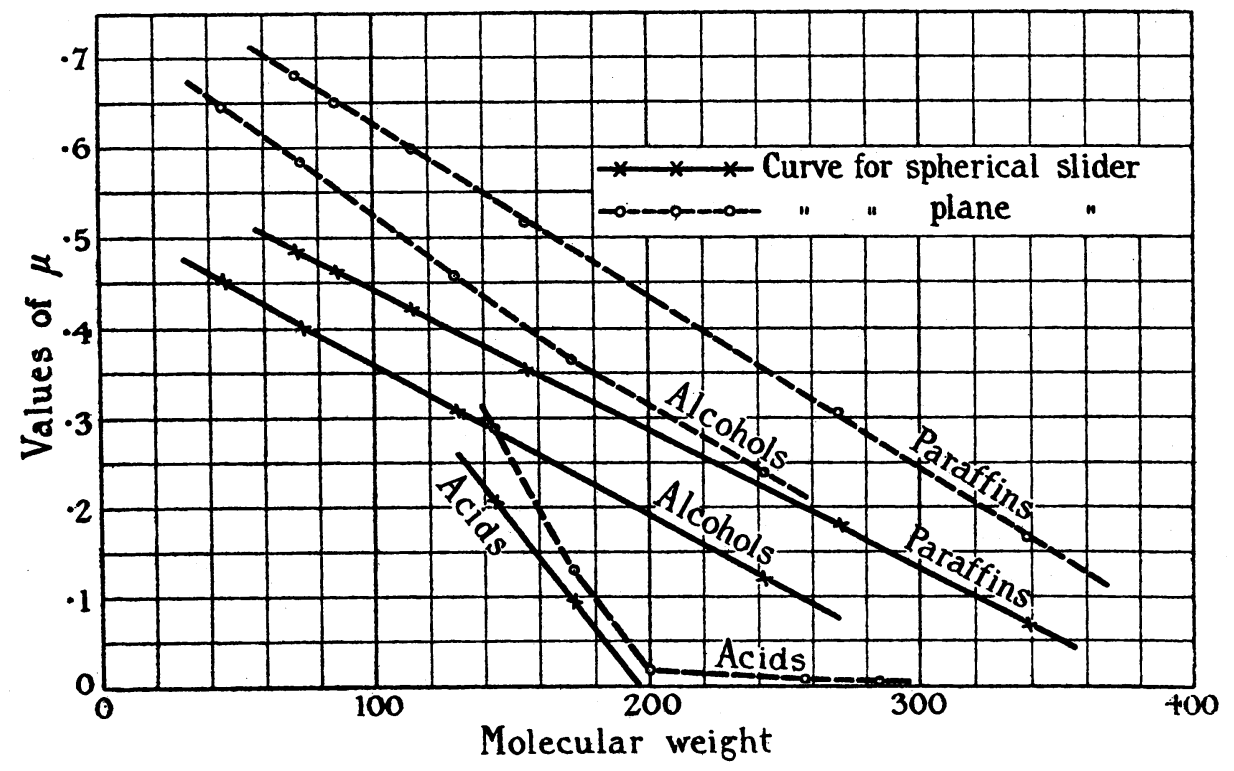

Figure 2. Dependence of friction coefficient on molecular weight for various homologous series[5].

Deeley[3,4], at around the same time, advanced an alternative hypothesis, however, involving a thick film consisting, essentially, of an organo-iron compound as the agent of surface oiliness. The monolayer vs. multilayer controversy was to continue for many decades, a cogent set of arguments against the monolayer theory being presented by Allen and Drauglis[6].

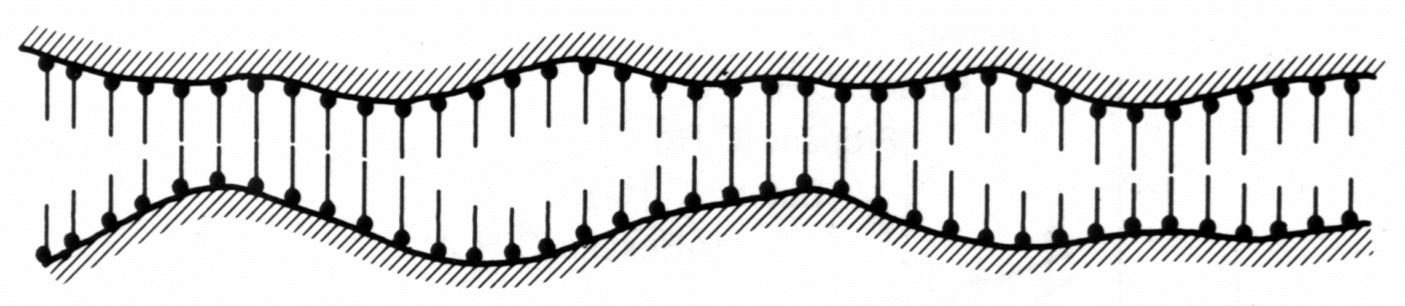

Figure 3. Hardy Boundary Model, adapted by [1].

Gregory[7] was to lend support to the monolayer theory by investigating the friction between clean cadmium surfaces lubricated by pure paraffin oil. In the absence of additives, he measured $\mu$ (static) to be 0.6 , which was reduced by an order of magnitude in the presence of $1 \%$ dodecanoic (lauric) acid. In the presence of only $0.01 \%$ dodecanoic acid, $\mu$ was still only 0.1 , while a $0.001 \%$ acid concentration showed a $\mu$ value close $(0.45)$ to that of the pure paraffin oil, dropping, however, over a period of 12 hours to a value of 0.26 , suggesting the slow adsorption of a submonolayer quantity of acid onto the sliding surfaces. By using a $0.1 \%$ dodecanoic acid concentration and slowly extending the lubricated area, Gregory could calculate 
the thickness of lubricating layer that apparently yielded significantly reduced friction. This was calculated at somewhere between one and two molecular layers.

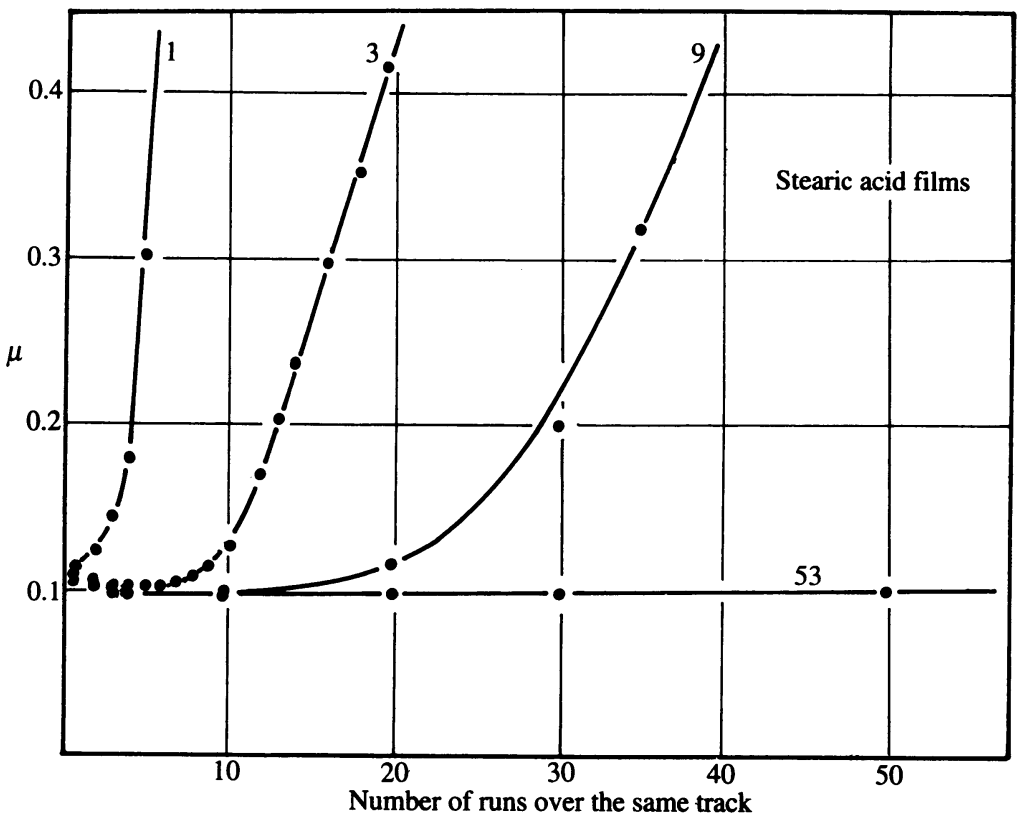

Figure 4. The friction of octadecanoic (stearic) acid films deposited on a stainless steel surface[7,8].

Bowden and Tabor took a tremendous step forward in the scientific treatment of boundary lubrication with the publication of their book "Friction and Lubrication of Solids" in 1950[7]. They showed that while a monolayer of octadecanoic (stearic) acid deposited on stainless steel by means of the Langmuir-Blodgett (LB) technique could indeed produce a low $\mu$ of 0.1 against a stainless steel slider, this value increased to 0.3 after five passes (Figure 4). The friction-reduction effect of three LBdeposited octadecanoic acid monolayers was more durable, with the $\mu=0.1$ value persisting for some half-dozen passes. Nine monolayers performed even better, with $\mu=0.3$ only being reached after 35 passes, and 53 monolayers provided an apparently constant value of $\mu=0.1$. Thus it was shown that while a single monolayer of a polar molecule can reduce friction, it is far from robust, and requires continuous replenishment. This is the situation, of course, in an oil containing the molecule as an additive at a reasonable concentration. Bowden and Tabor also found that molecular structure played a role in boundary lubrication ability, with nonanoic acid (C9) being the shortest acid that could show any boundary lubrication ability. Looking at this in terms of a modern interpretation of the Hardy model, this would correspond to the minimum chain length that, by virtue of inter-chain van der Waals' forces, could maintain itself in an ordered, tails-up arrangement. Similar arguments can be used to explain why branched molecules are less effective boundary lubricants than their 
straight-chain counterparts: The side chains simply impair close packing of the molecules[9,10].

Table 1. Coefficients of sliding friction at room temperature [7,8].

\begin{tabular}{l|ll} 
Surfaces & $\begin{array}{l}\text { Lubricant: } \\
\text { Paraffin oil }\end{array}$ & Paraffin oil + 1\% dodecanoic acid \\
\hline Nickel & 0.3 & 0.28 \\
Chromium & 0.3 & 0.3 \\
Platinum & 0.28 & 0.25 \\
Silver & 0.8 & 0.7 \\
& & \\
Copper & 0.3 & 0.08 \\
Cadmium & 0.45 & 0.05 \\
Zinc & 0.2 & 0.04 \\
Magnesium & 0.5 & 0.08
\end{tabular}

The substrate dependence of lubrication by oil additives can also provide useful insights. In Table 1 , the effect on $\mu$ of $1 \%$ dodecanoic acid in paraffin oil used with nickel, chromium, platinum, and silver surfaces is shown to be slight. On copper, cadmium, zinc, and magnesium surfaces, however, friction reduction by an order of magnitude was observed. This study suggests that reaction of the additive with the substrate (presumably to form a metal "soap") has occurred for the latter group. Temperature dependence is also revealing (Figure 5): Many solid lubricants, such as lead or solid alkanes, will effectively lubricate surfaces up their melting points, after which they can no longer hold the sliding surfaces apart. While docosane (C22, m.p. $=44^{\circ} \mathrm{C}$ ) and octadecanoic acid (m.p. $=69^{\circ} \mathrm{C}$ ) effectively lubricate platinum surfaces up to their melting points, dodecanoic acid lubricates copper surfaces up to $90^{\circ} \mathrm{C}$, which corresponds to the softening point of copper dodecanoate. Moreover, dodecanoic acid on copper shows similar lubrication behavior to copper dodecanoate on platinum! This might suggest that copper dodecanoate is involved in both cases. It is also interesting to note that sodium octadecanoate (m.p. $=260^{\circ} \mathrm{C}$ ) lubricates steel surfaces up to $280^{\circ} \mathrm{C}$. 


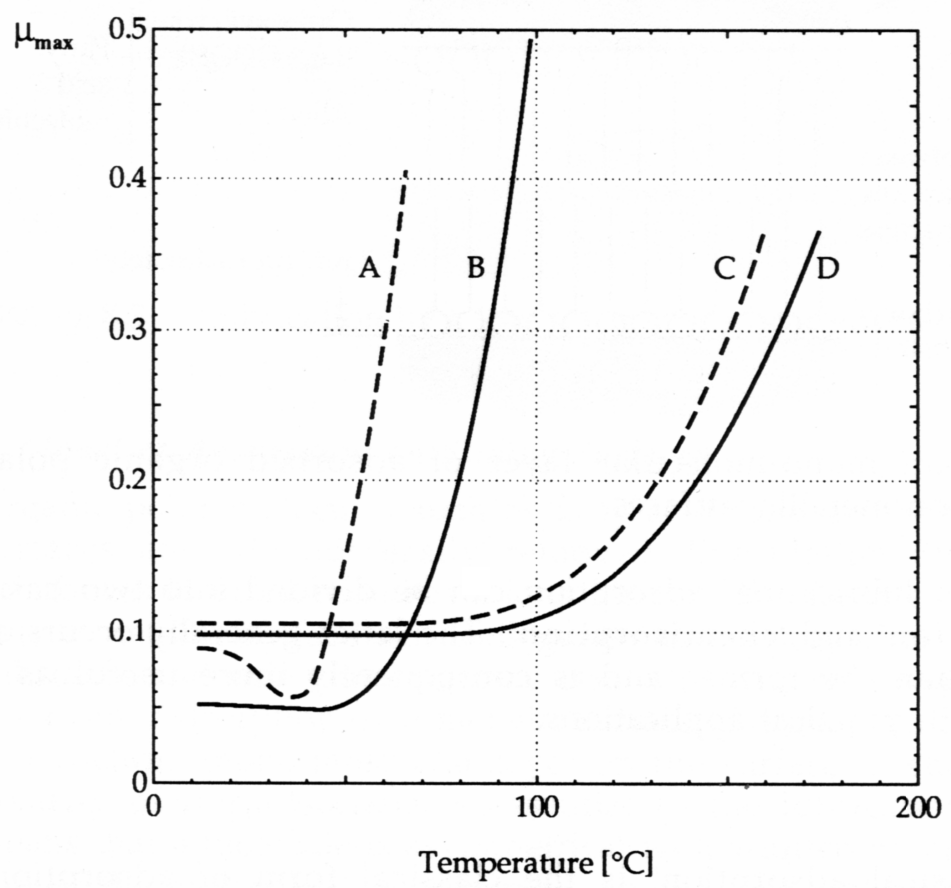

Figure 5. Effect of temperature on friction of platinum and copper surfaces, lubricated by docosane and fatty acids. Curves A) solid docosane $\left(m . p .=44^{\circ} \mathrm{C}\right) \mathrm{on} \mathrm{Pt}$, B) solid octadecanoic acid $\left(m . p .=69^{\circ} \mathrm{C}\right)$ on Pt, C) solid copper dodecanoate ( softening point $=110^{\circ} \mathrm{C}$ ) on Pt, D) $1 \%$ dodecanoic acid in paraffin oil on Cu.[7,10]

Clearly the lubrication ability of octadecanoic and dodecanoic acids on reactive metals involves more than a simple adsorbed molecular film, although it is also clear from results described earlier that a simple molecular layer can serve as the basis for boundary lubrication. More light has been shed on this apparently confusing issue by a recent set of experiments. Fischer et al.[11] used X-ray absorption spectroscopy to show that octadecanoic acid adsorbs on copper in a mixture of bidentate and monodentate states, with the chains oriented close to the surface normal. At this stage, the spectra appear very similar to those of an octadecanoic acid standard. Tribological treatment (rubbing in air against a clean $\mathrm{Cu}$ surface in a reciprocating motion for ten passes with a normal force of $1 \mathrm{~N}$ ) induces a conversion of some of the monodentate states into the bidentate form, and an enhanced orientation towards the surface normal, while showing no loss of the organic layer. X-ray absorption measurement of the tribologically treated surface reveals a spectrum that is very similar to that of copper octadecanoate. Thus it seems as if the octadecanoic acid monolayer is converted almost instantaneously into the corresponding octadecanoate upon rubbing, although the chain orientation is still very much as Hardy envisaged.

Possibly the recent results that provide the most insight into the monolayer/multilayer controversy have been generated by Ratoi et al.[12], who used the method of ultrathin 
film interferometry[13] to monitor the lubricant film thickness during rolling contact of bearing steel on glass. When the lubricant used is purified hexadecane, the logarithm of the film thickness varies linearly as the logarithm of the rolling speed (Figure 6a), as predicted from elastohydrodynamic lubrication theory, down to a thickness of around $1 \mathrm{~nm}$ (interestingly, due to elastic conformality, this holds despite the 12-nm roughness of the contacts). In the presence of carboxylic acids, the situation is more complex, and a deviation from linearity is observed at low speeds. In the case of dry 0.1 wt.\% octadecanoic acid in hexadecane (Figure 6b), a deviation from the hexadecane results of around $2 \mathrm{~nm}$ was observed at the lowest speeds, although this reduced to $<1 \mathrm{~nm}$ upon stopping the relative motion of the surfaces. When the same system was examined in the presence of water, however, the results were quite different (Figure 6c): A much thicker film was formed at low speeds. The film thickness was speed-dependent, reaching about 8-12nm thick at its maximum, but disappearing almost completely as rolling speed was increased. Upon reducing the rolling speed once again, the film slowly reformed. Upon stopping the machine, a film of some $2-4 \mathrm{~nm}$ remained in the contact region. Similar wet and dry behavior was observed for eicosanoic (C20, arachidic) acid. Interestingly, when stainless steel was used in the contact instead of bearing steel, no film was found to form upon testing with wet octadecanoic acid in hexadecane, suggesting that the above observations are due to a corrosive reaction of the additive with the steel substrate.

The above observations can be explained in terms of the water-induced oxidation of iron to $\mathrm{Fe}(\mathrm{II}) / \mathrm{Fe}$ (III), which then goes on to form the carboxylate thick films. Similar behaviour has been observed previously with copper carboxylates in mineral oil on a steel surface[14], where a 40nm boundary film forms slowly at low speeds, collapsing at high speeds. In general, redox reactions play an important role in the formation and removal of these thicker films[15], with the films first forming in the $\mathrm{Fe}(\mathrm{II})$ state, which is insoluble in oil, and slowly oxidizing to the oil-soluble Fe(III) state. Thus, as a system moves from boundary to EHL conditions, the boundary film is no longer being formed and dissolves away. Extending this approach, by judicious addition of various metal carboxylates, Ratoi et al.[15] found that carboxylates of metals below iron in the electrochemical series (e.g. copper) reacted to form iron carboxylate boundary films, while carboxylates of metals above iron (e.g. zinc, magnesium) formed no boundary films at all. In summary, ultrathin film interferometry has shown that either monolayers or multilayers can be formed from carboxylic acid additives, depending on the prevailing tribological conditions. The relative lubricating efficiency of the two possibilities is currently under investigation. 


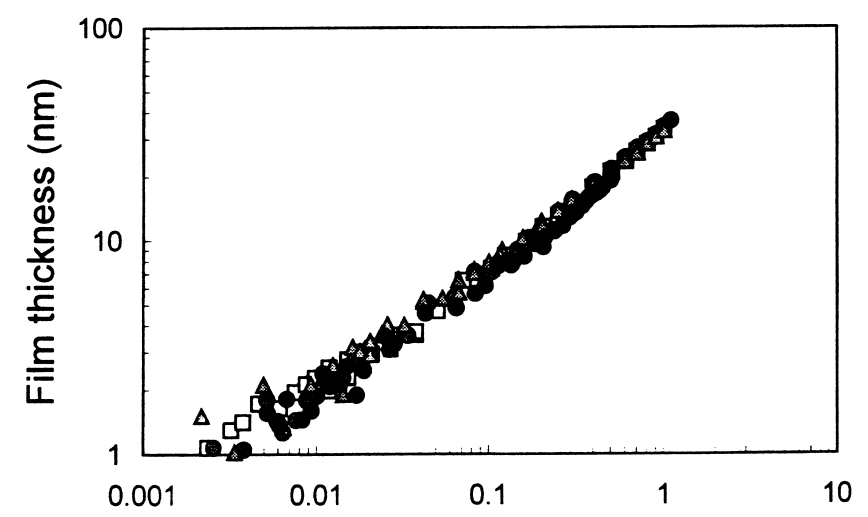

a)

Mean rolling speed $(\mathrm{m} / \mathrm{s})$

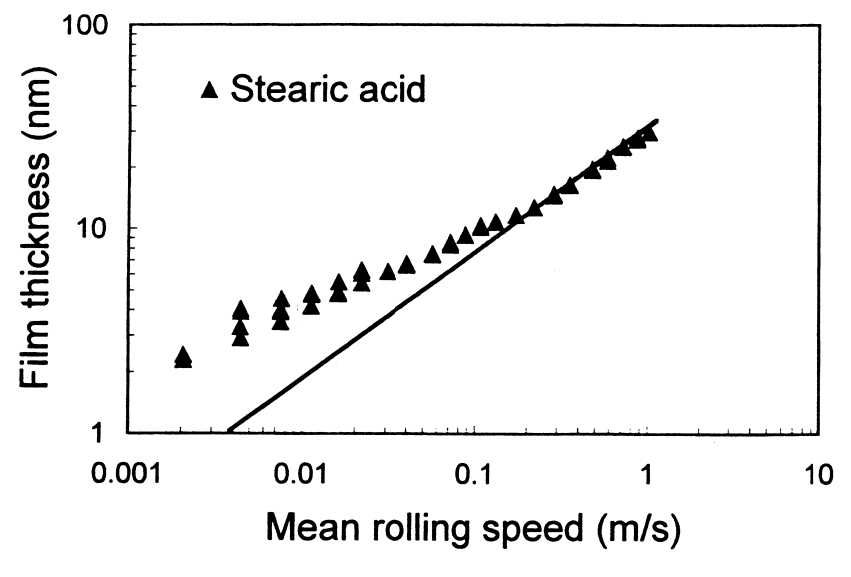

b)

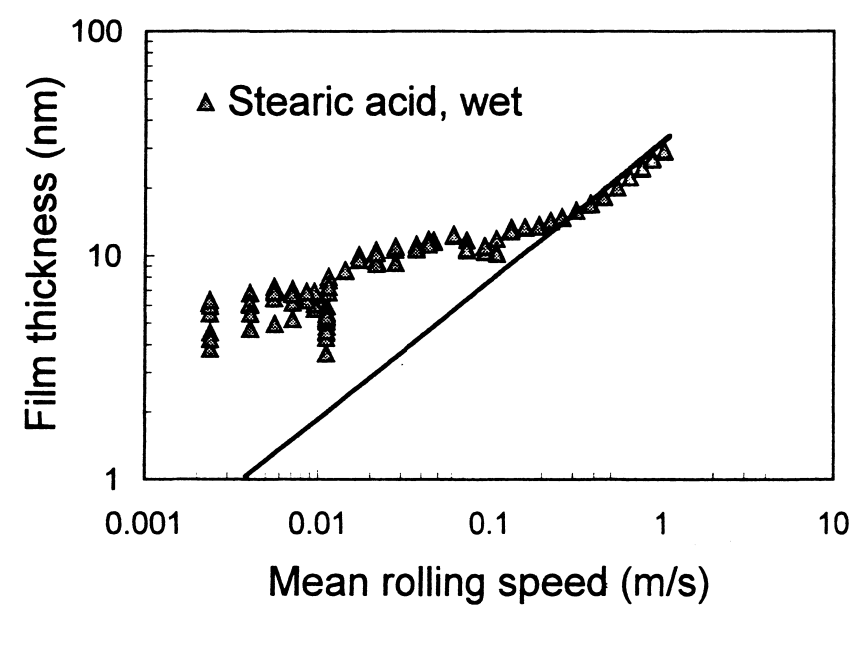

Figure 6. EHD film formation measured by ultrathin film interferometry a) purified hexadecane, b) dry $0.1 \%$ octadecanoic (stearic) acid in hexadecane (the solid line is pure hexadecane), c) wet $0.1 \%$ octadecanoic acid in hexadecane.[12]

Viscous near-surface layers

In the previous section, we have seen that multilayers of carboxylates can form in additive-modified lubricants in the presence of moisture. These lubricate the rolling 
contact by means of their locally high viscosity. However, even in the absence of additives, there have been suggestions or reports over the years of a locally high viscosity at the surface, starting with Deeley's suggestion in the 1920s of a "friction surface, which is a compound of oil and metal"'[3,4]. Çavdar and Ludema[16-18] studied the lubrication of steel by additive-free mineral oils by means of in situ ellipsometry and found that after some 20 minutes, a 5-10nm thick layer of organoiron compounds was formed on an oxide/carbide underlayer. Hsu[19] has actually analyzed oil samples that have been used to lubricate sliding contacts. Using gelpermeation chromatography, he was able to show that organo-iron compounds with molecular weights up to 100,000 were present in the case of a highly refined mineral oil lubricant. Hsu hypothesised that metal-catalyzed oil oxidation leads to a polymerisation mechanism.

Results from the surface forces apparatus (SFA) suggest that liquids in the immediate vicinity of surfaces are strongly influenced by that surface, with a phase behavior that is distinct from that of the bulk liquid. Israelachvili et al.[20] and Granick[21] have shown that the effective viscosities of thin liquid films can be several orders of magnitude higher than bulk values within one or two molecular layers of the surface and, very recently, SFA refractive-index studies by Heuberger et al.[22] have indicated fluctuations between phases resembling solids, liquids, and gases when cyclohexane is confined between mica surfaces at room temperature. Although interesting, the significance of these SFA observations under real tribological conditions remains to be established.

\section{Boundary lubrication in natural joints}

Although many different modes of lubrication are present in natural joints, such as those in the hip and in the knee[23], boundary lubrication plays an important role after periods of inactivity, such as sleeping, or reading this article. The natural lubricant, synovial fluid, is similar to blood serum in composition, but has a somewhat higher level of hyaluronic acid, which plays a role in maintaining a higher viscosity in the medium-useful in the hydrodynamic modes of lubrication. Also present in the fluid are many different kinds of proteins, lipids and inorganic salts. While there is some discussion in the literature as to whether lipids play an important tribological role, it is now commonly accepted that proteins are important boundary lubricants.

Lubrication in the natural joint is highly relevant for understanding the progress of certain joint disorders, such as arthritis. The sliding surfaces consist of cartilage, which contains proteins and polysaccharides, such as chondroitin sulfate. In artificial joints, however, which are being increasingly implanted, as a consequence of the aging population and of improved technology, sliding surfaces generally consist of Co-Cr-alloys, ceramics, or ultrahigh molecular weight polyethylene (UHMWPE), all 
of which have certain advantages and disadvantages. Wear of UHMWPE has been an important issue in recent years, since PE particles can confuse the body's immune system, leading to a response that ultimately causes loosening of the implant in the bone, requiring a further operation.

Widmer et al.[24] have shown that the surface hydrophilicity of the sliding surfaces in a hip implant can have a major effect on both protein adsorption and frictional behavior. Using oxygen plasma treatment to render a polyethylene surface more hydrophilic, they were able to show a reduction of dynamic friction by around $50 \%$ in protein-containing solutions. In salt solutions (Ringer's) this effect did not occur. It was also observed that the plasma treatment led to an increase in the amount of protein that adsorbed on the polyethylene surface, lending support to the hypothesis that proteins denature and spread out on hydrophobic surfaces, and are less able to function efficiently as boundary lubricants. On hydrophilic surfaces, they maintain a more compact shape, can therefore pack better onto the surface, and function better as boundary lubricants.

\section{Summary}

In a sense, modern analytical methods have not so much led to the confirmation of one particular proposed mechanism for boundary lubrication, but rather have shown that several different mechanisms, from Hardy's monolayers, through the formation of Deeley's organo-iron compounds and other thick reaction layers, to near-surface layers of pure lubricant with enhanced viscosity are all possible under different tribological situations. The relative importance of each mechanism under different sets of real conditions is not yet completely clear, but is currently under investigation by a number of research groups.

\section{Zinc Dialkyldithiophosphate}

\section{Background}

There are few lubricant additives that have received as much attention in the literature as zinc dialkyldithiophosphate (“ZnDTP”, “ZDTP”, “ZDDP” or “ZDP”). Originally added to lubricating oil as an antioxidant[25], it was rapidly discovered that it also functioned as a highly effective antiwear and extreme-pressure additive, and is an essential ingredient in the vast majority of current lubricant formulations. An important role of ZnDTP in such lubricants is to protect surfaces under conditions where elastohydrodynamic lubrication breaks down, such as in counterformal contacts present in valve-train systems between cams and followers[26]. In order to function effectively, films of this kind must possess a shear strength that is sufficiently low to ensure that the shear plane resides within the protective layer itself, while being high enough to maintain layer integrity[27]. Clearly the rate of formation 
of the film must also keep pace with any film wear that occurs, while not being so great that it unnecessarily corrodes the substrate. Furthermore, the films should inhibit adhesion between the contacting surfaces. All-in-all, this is a tough set of requirements for an additive, but has been met by ZnDTP with great success.

One of the reasons for the effectiveness of $\mathrm{ZnDTP}$, is its ability to function in different ways, depending on the nature and severity of the tribological conditions. It is in this sense a "smart" material[27]. Thus, the many apparently conflicting results obtained from studies of this system have often been illustrating different facets of the rich thermal and tribochemical behaviour of this molecule, or rather family of molecules, since many variations on the basic chemistry (Figure 7), as well as their combinations are commercially employed.

In addition to academic curiosity, there are good practical reasons for trying to understanding the mechanism by which ZnDTP functions. Among these is the undesirable propensity for engines that are exposed to these additives to produce zincand phosphorus-containing emissions, which are potentially deleterious to both downstream catalyst performance and to the environment. Clearly, a better understanding of the ZnDTP surface-reaction mechanisms should assist in the development of more benign alternatives.
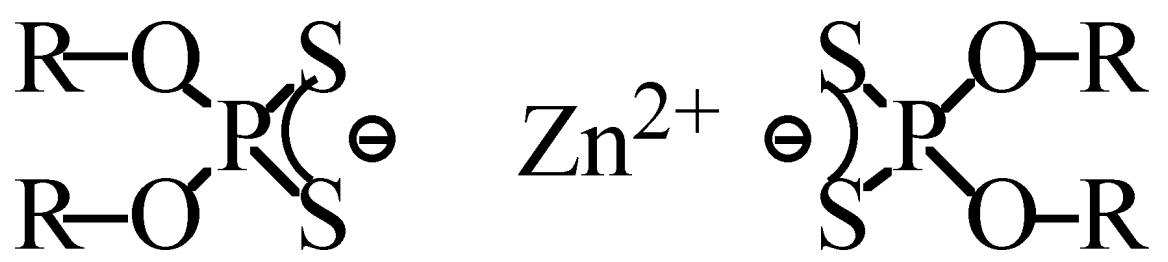

Figure 7. Structure of ZnDTP. R can be a primary or secondary alkyl group, or an aryl functionality.

\section{Analytical approaches}

One particularly daunting aspect of the generally daunting ZnDTP literature is that virtually every weapon in the surface-analysis arsenal has been brought to bear upon the problem, including Auger electron spectroscopy (AES)[28,29], X-ray photoelectron spectroscopy (XPS)[30,31], near-edge X-ray absorption fine structure (NEXAFS, or XANES)[30,32-39], Fourier transform infrared spectroscopy (FTIR)[40], time-of-flight secondary-ion mass spectroscopy (ToF-SIMS)[41], scanning force microscopy (SFM)[42,43], the surface forces apparatus (SFA)[27,44], transmission electron microscopy (TEM)[39], scanning electron microscopy (SEM)[45], extended X-ray absorption fine structure (EXAFS)[36] and profilometry[45], as well as in situ tribometry methods such as the direct-observation wear machine (DOWM)[46] and ultra-thin film interferometry[47]. 


\section{Summary of film-formation mechanism}

By the end of the twentieth century, a general picture of the mechanism for alkylZnDTP molecules with steel surfaces had emerged. The molecule appears to interact weakly with the steel surface (possibly through the sulphur atoms[48], according to quantum-chemical calculations) at room temperature[44], starting to catalytically decompose around $50^{\circ} \mathrm{C}$ in the presence of the iron oxide substrate[49]. Upon reaching around $100^{\circ} \mathrm{C}$, either through simple thermal treatment or by tribo-induced flash heating, the ZnDTP starts to undergo thermo-oxidative decomposition, due to the presence of either oxygen or peroxide radicals in the oil[50]. There is evidence from XANES studies[35] as well as from ${ }^{31} \mathrm{P}-\mathrm{NMR}[51,52]$ that the molecule first undergoes a rearrangement to form a "linkage isomer", LI-ZnDTP, in solution:

$$
\underset{\mathrm{ZnDTP}}{\mathrm{Zn}\left[(\mathrm{RO})_{2} \mathrm{PS}_{2}\right]_{2}} \rightarrow \underset{\mathrm{Zn}\left[\mathrm{O}_{2} \mathrm{P}(\mathrm{SR})_{2}\right]_{2}}{\mathrm{ZI}-\mathrm{ZnDTP}}
$$

This species, following reaction with unchanged ZnDTP, goes on to form a longchain glassy zinc polyphosphate and polythiophosphate coating on the surface, as inferred from optical microscopy[45], XANES[33] and TEM of wear debris[50]. An organosulphur species is released into the lubricant, which, under extreme conditions, reacts with nascent iron surfaces to form $\mathrm{FeS}$, which has been detected within the polyphosphate matrix in TEM studies (Figure 8)[50] and immediately next to the steel substrate using AES[29]. Partially reacted, semipolymerised alkylphosphates seem to form a viscous layer above the harder polyphosphates, as determined by ToFSIMS[41] and SFA[27] studies.
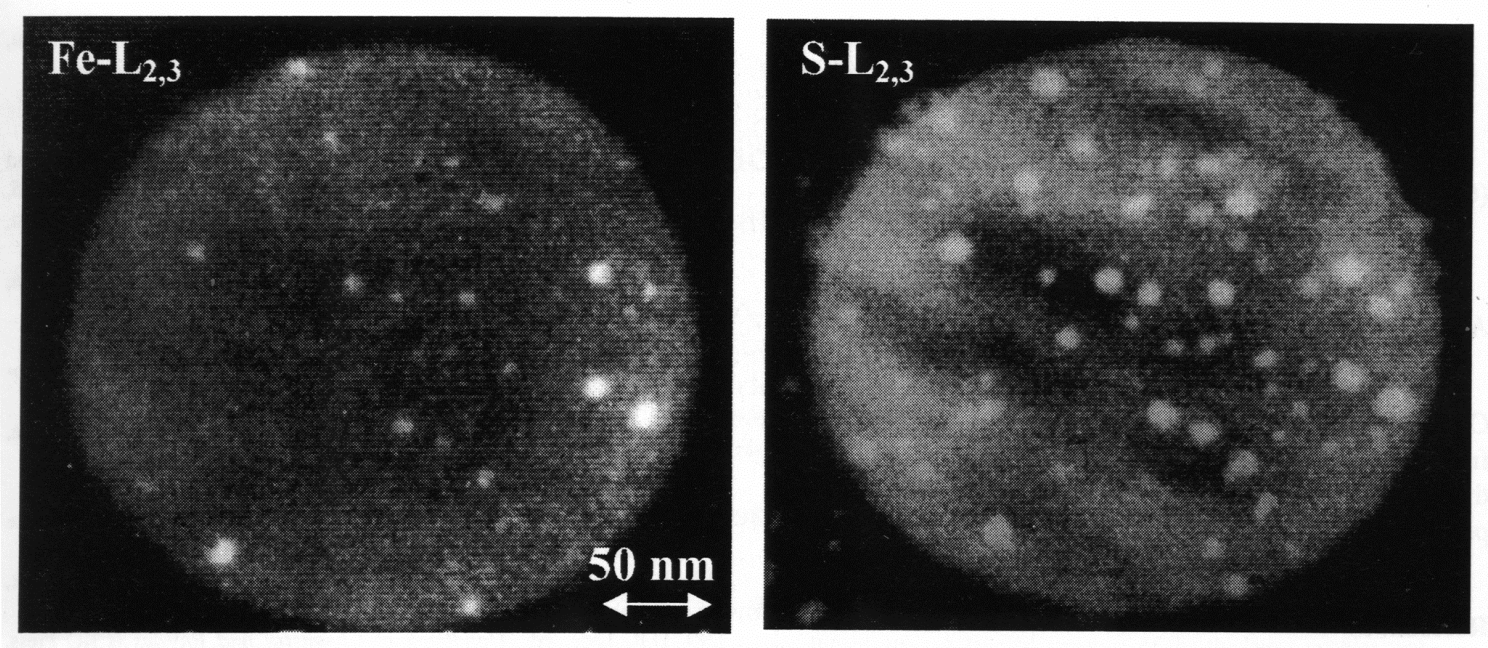

Figure 8. Energy-filtering TEM image of iron and sulphur in a wear particle originating from severe plane-on-plane wear tests in the presence of ZnDTP. The 
images show the existence of nm-scale precipitates of iron sulphide in the phosphate based matrix.[50]

Many of the reactions involved in dialkyldithiophosphate decomposition can be rationalized using Pearson's theory of hard acids and bases[50,53], where the $\mathrm{P}=\mathrm{S}$ group, for example, is a typical soft base (low nuclear charge, high polarizability), which is more likely to react with a soft acid (e.g. tetravalent carbon), as in the LIZnDTP formation reaction described above, while a hard base (high nuclear charge, low polarizability, e.g. $\mathrm{P}=\mathrm{O}$ ) is likely to react preferentially with hard acids (e.g. tetravalent $\mathrm{P}$, or $\mathrm{H}^{+}$), leading to the reaction[52]

$$
\equiv \mathrm{P}=\mathrm{O}+\equiv \mathrm{P}-\mathrm{SR} \rightarrow \ldots \equiv \mathrm{P}^{+}-\mathrm{O}-\mathrm{P} \equiv \_ \text {SR }
$$

Similarly, looking at the iron oxide "digestion" process, since $\mathrm{Fe}^{3+}$ is a harder acid than $\mathrm{Zn}^{2+}$, ferric oxide will react with (hard) zinc phosphates to produce zinc iron phosphate and zinc oxide. Zinc oxide may go on to react with organosulphur compounds to produce zinc sulphide, which has the advantage of being mechanically softer than its oxide counterpart.

\section{Studies of film structure, composition and thickness}

Many studies have focused on the thickness of the films produced by ZnDTP. Gunsel et al.[47] used ultra-thin-film interferometry to monitor ZnDTP film formation at various temperatures. A solid film appeared to be forming, under rolling conditions, once a threshold temperature of $130^{\circ} \mathrm{C}$ was reached. At $200^{\circ} \mathrm{C}$, the film grew, over a period of an hour, to a saturation thickness of just over $40 \mathrm{~nm}$. Using a similar method, which enabled reaction films to be observed outside the contact in a mixed rolling/sliding regime, Taylor et al.[54] were able to show that the films could be as thick as 200nm, but depended strongly on the slide-roll ratio. XANES studies[38] have shown that the films are of the order of 40-100nm thick, depending on the concentration of ZnDTP in solution. 


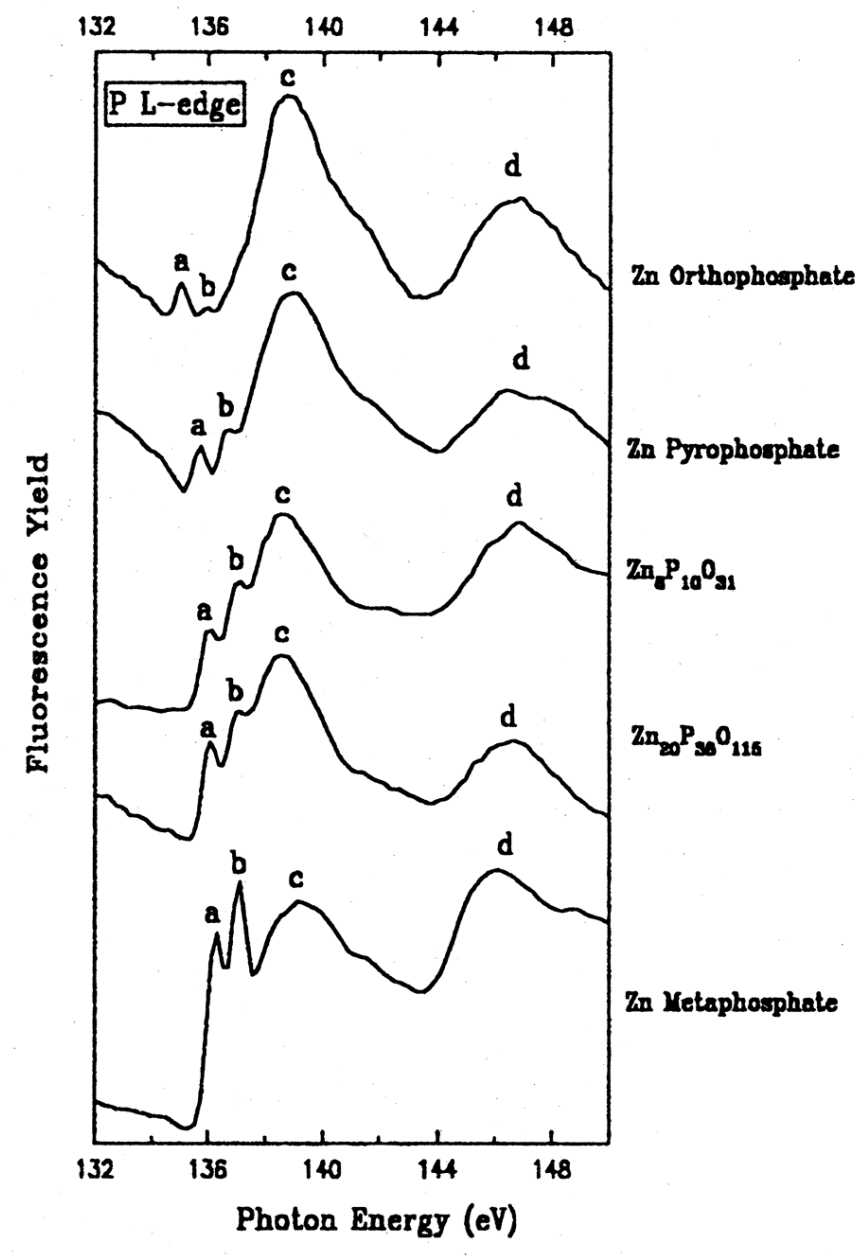

Figure 9. Phosphorus L-Edge XANES spectra of polyphosphate glasses [30].

XANES has proved to be a particularly useful tool for examining the growth of polyphosphate chains on the steel surface in the presence of ZnDTP. Using specially synthesized zinc polyphosphate chains of various lengths[30], Kasrai and co-workers were able to show that the fine structure in the phosphorus L-edge in the XANES spectrum is a sensitive indicator of polyphosphate chain length (Figure 9), while the height of the corresponding K-edge can serve as a reliable indicator of polyphosphate film thickness[38].

XANES spectra can either be monitored by total electron yield (TEY) or fluorescence yield (FY). These two approaches are complementary, the former having a surface sensitivity of some $5 \mathrm{~nm}$, while the latter probes $50 \mathrm{~nm}$ (at the P L-edge, and $1 \mu \mathrm{m}$ for the K-edge) into the sample. By using both methods on the same sample, an indication of the relative composition of the outer and inner regions of the film may be obtained. Bancroft et al.[34] were thus able to monitor the fate of tribo- and thermally generated films. Immediately after formation, the outer surface (from TEY) consisted of long-chain polyphosphate, while the bulk (from FY) shows only short- 
chain phosphates. Upon rubbing the films in pure base oil (i.e. without the possibility of film replenishment), they appear to remain on the surface for many hours, although the XANES fine structure shows that the chain length decreases markedly with time. It is thought that the reactions are of the general form:

$$
\begin{aligned}
& 5 \mathrm{Zn}\left(\mathrm{PO}_{3}\right)_{2}+\mathrm{Fe}_{2} \mathrm{O}_{3} \rightarrow \mathrm{Fe}_{2} \mathrm{Zn}_{3} \mathrm{P}_{10} \mathrm{O}_{31}+2 \mathrm{ZnO} \\
& \text { or } \\
& \mathrm{Zn}\left(\mathrm{PO}_{3}\right)_{2}+2 \mathrm{FeO} \rightarrow \mathrm{Fe}_{2} \mathrm{Zn}\left(\mathrm{PO}_{4}\right)_{2} \\
& \text { Long-chain phosphate } \quad \text { short-chain phosphate }
\end{aligned}
$$

In other words, the film is intergrown with the oxide on the steel, which presumably also enhances mechanical stability[34]. The mechanism also shows that the glass can function as a digestion agent for iron oxides, which are abrasive and therefore enhance wear. The tribo-generated films appear to last for days when being rubbed in base oil, and are still some $30 \mathrm{~nm}$ thick after 6 hours. The thermal films appear to be somewhat less robust.

All of the studies just described measure average properties over a macroscopic area. However, there is considerable evidence that the antiwear films produced are highly uneven[54]. Sheasby and Nisenholz Rafael[45] detected the existence of $20 \mu \mathrm{m}$ diameter "pads" of ZnDTP-derived antiwear film by means of SEM. Graham et al.[43] went on to extend this work, using scanning force microscopy to examine antiwear films derived from both alkyl and aryl ZnDTPs. The alkyl additives indeed yielded $10-20 \mu$ m-diameter pads with flattened tops, elongated in the sliding direction and surrounded by lower, smaller pads. These authors also applied the interfacial force microscope (IFM) to examine the mechanical properties of these pads. At the center of the large pads, indentation modulus values as high as $209 \mathrm{GPa}$ were measured (compare to $220 \mathrm{GPa}$ for the substrate 52100 steel!), as well as a very elastic response to indentation. The aryl-ZnDTP-derived films, which display greatly inferior wear resistance, did not appear to contain large pads, neither did they display such high indentation moduli. Using spectromicroscopy (spatially-resolved XANES) on similarly produced films, Canning et al.[37] showed that the large pads produced from the alkyl-ZnDTP consisted of long-chain polyphosphates, while the smaller pads, and all features in the aryl-derived films, contained short-chain phosphates only.

In many of the analytical approaches used to investigate this system, it has been necessary to rinse the sample in organic solvent prior to analysis. Depending on the aspect of the films under investigation, some workers have found that solvent washing does not affect the outcome of the analysis[39], while others have noticed a significant effect[27,41]. Bec et al.[27] used a unique version of the SFA to 
investigate fully formed films both with and without solvent washing. They found that in the absence of solvent washing, a viscous layer, several hundred nanometers thick and displaying a hardness in the MPa range, was present at the outer surface. This presumably corresponds to a partially reacted ZnDTP layer, consisting of alkylphosphates[41], which serves both as a reserve for polyphosphate formation and as a low shear-strength layer. Solvent washing apparently removed the alkylphosphate layer, leaving the polyphosphate layer, with hardness in the GPa range, largely intact. This layer was patchy, as found by many other authors, with features some $10 \mu \mathrm{m}$ across. It seems unlikely that there is a clear interface between the alkylphosphate and polyphosphate layers, but rather a gradual transition. An interesting observation by Bec et al.[27] was the similarity in the hardness value of the polyphosphate layer to the mean pressure applied during the previous tribological testing. This suggests an accommodation on the part of the polyphosphate film to the contact pressure to which it is exposed. The overall structure of the produced films is summarized in Figure 10.

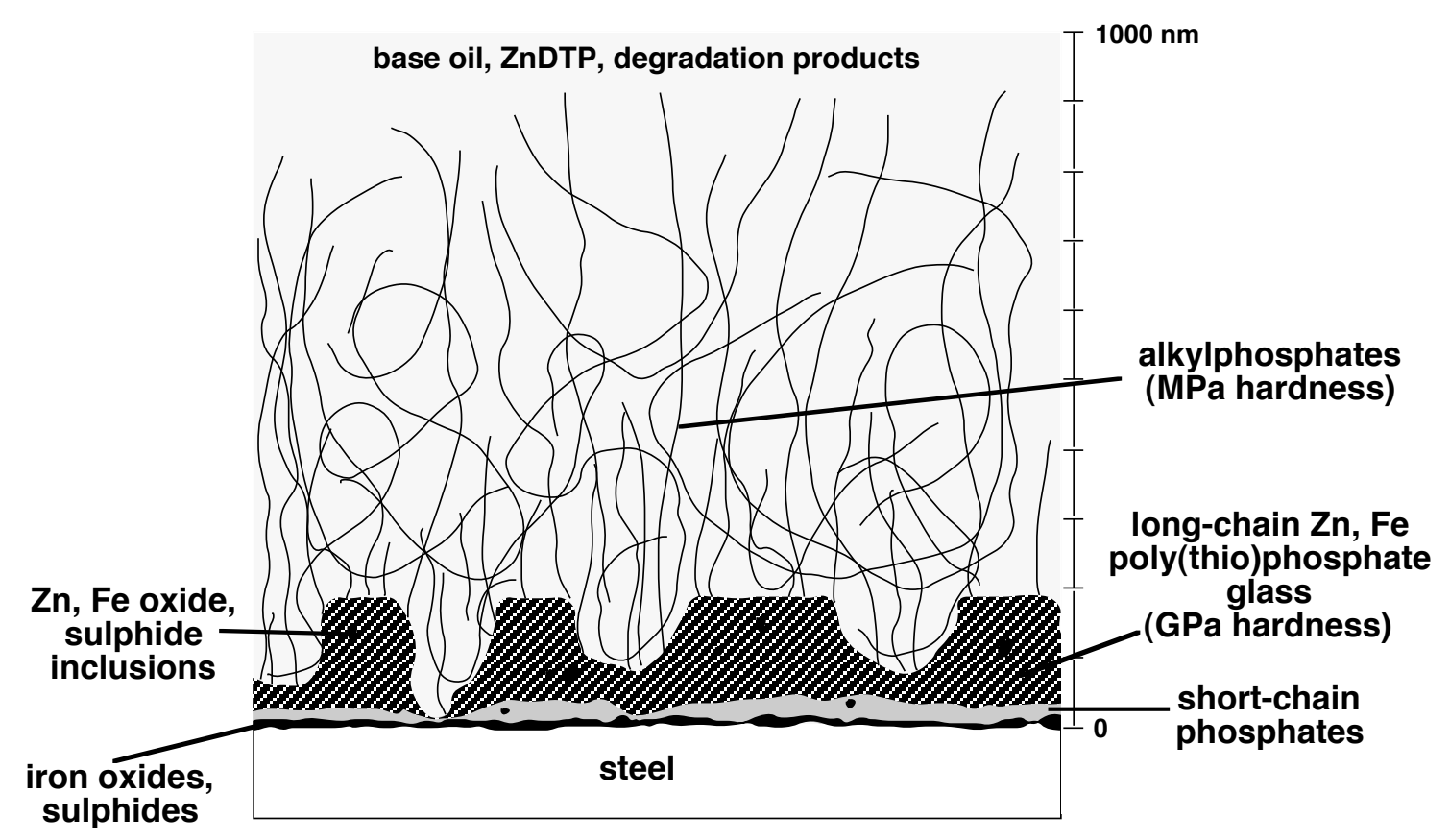

Figure 10: Schematic of ZnDTP antiwear film structure

As can be seen from the above, the formation, structure and function of ZnDTPderived antiwear films is highly complex. Thanks to the developments in surface analytical techniques over the last thirty years, and their judicious combination, a fairly comprehensive picture has emerged. The challenge for the additive chemist is now the application of this knowledge in the design of improved antiwear additives with greater environmental compatibility. 


\section{Hard-Disk Lubrication}

At the heart of the hard disk drives used to store the vast majority of data on the modern personal computer is the head-disk interface. The disk, of course, is the medium on which the data is written and from which it is read. The head is the device that does the reading and the writing. Although they come in several shapes and sizes, the most commonly shipped drives currently have disks that are $95 \mathrm{~mm}$ in diameter and are fabricated from an AlMg alloy. The size of the disk has continuously decreased over the years and as the technology is developing extremely rapidly it will, no doubt, continue to do so. The data is written into a thin $(\sim 200 \AA)$ layer of magnetic material that is sputtered onto the surface of the disk. As the disk spins at speeds on the order of 10,000 rpm, the read-write head flies over its surface on an air-bearing at a height of $\sim 200 \AA$. With such incredibly fine tolerances, periodic contacts between the head and the disk surface are unavoidable and the need to protect the disk surface from damage creates one of the most interesting problems in modern tribology [55-57].

To give some idea of the magnitude of the problem associated with protecting the head-disk interface from damage consider a simple scaling of the device up to more familiar macroscopic dimensions. The read-write head is $\sim 2 \mathrm{~mm}$ in length. If this is scaled linearly $\left(\times 10^{4}\right)$ to the size of a small airplane, $20 \mathrm{~m}$ in length, then this airplane is flying at $\sim 400,000 \mathrm{kph}$ at an altitude of $\sim 0.2 \mathrm{~mm}$ ! Furthermore, the problems associated with operating these devices at such fine tolerances will only continue to become more severe in the future. There is a constant market drive to increase the density of data stored on magnetic media. Products currently being shipped have areal densities of about $20 \mathrm{Gbit} / \mathrm{in}^{2}$. This number has been increasing by $60 \%$ per year for the past decade and will continue to do so for the foreseeable future. Current targets are set at $100 \mathrm{Gbit} / \mathrm{in}^{2}$. Achieving higher recording densities requires smaller bits and this in turn requires the head to fly even closer to the disk surface in order to be able to sense the magnetic field from such a small area[58,59].

Needless to say, the protection of magnetic data poses one of the most high-tech and most demanding problems in modern tribology. The surface of the disk is protected from the read-write head by a thin (50-100 $\AA$ ) films of sputtered carbon, which, in

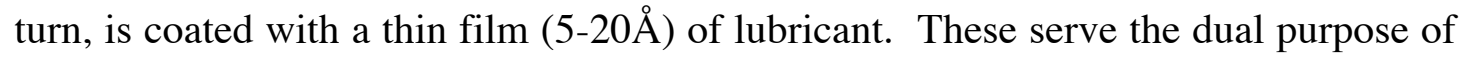
providing both mechanical and corrosion protection for the magnetic media. The composition and structure of the head-disk interface is illustrated in figure 11. 


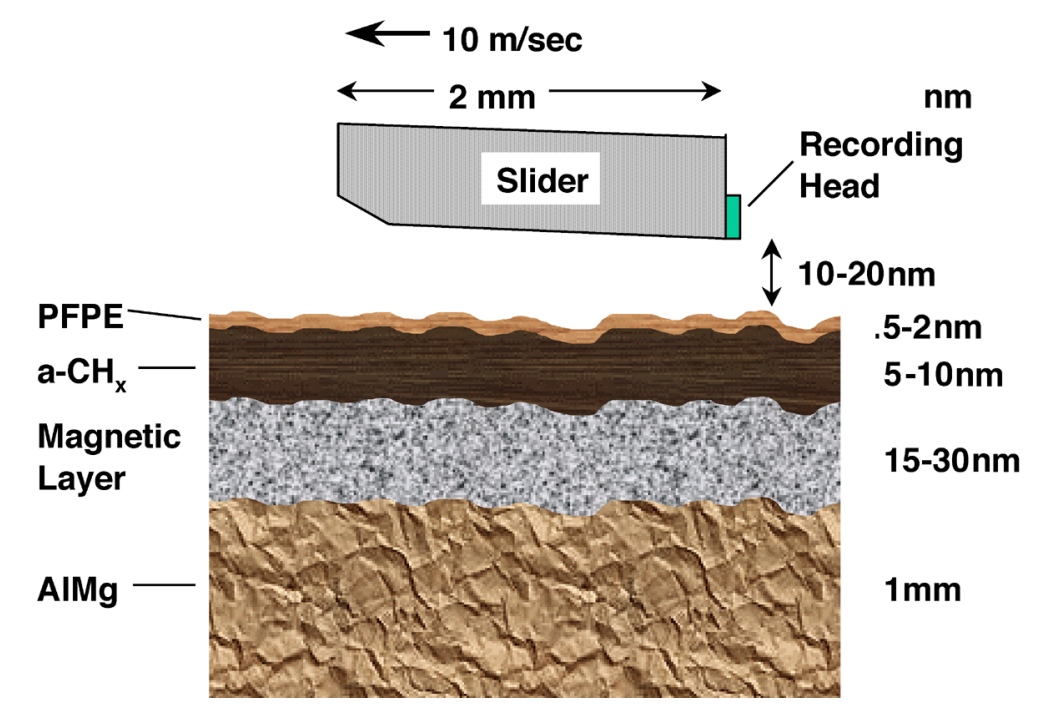

Figure 11. Illustration of the head-disk interface in a hard disk drive.

The sputtered carbon films that are used to protect magnetic media are usually of two types: amorphous hydrogenated carbon $\left(\mathrm{a}-\mathrm{CH}_{\mathrm{x}}\right)$ and amorphous nitrogenated carbon $\left(\mathrm{a}-\mathrm{CN}_{\mathrm{x}}\right)$. In addition, there are, of course, hybrid materials: a- $\mathrm{CH}_{\mathrm{x}} \mathrm{N}_{\mathrm{y}}$. The carbon is sputtered from targets in the presence of $\mathrm{H}_{2}$ and/or $\mathrm{N}_{2}$. These are quite complex materials and the details of their structure at the atomic level are not completely known. Although these are sputtered onto the surface in vacuum, they are exposed to air immediately afterwards and thus their surfaces are partially oxidized. Many analysis methods have been used to probe the composition and structure of these surfaces. XPS has been used extensively to determine $\mathrm{O}$ and $\mathrm{N}$ concentrations at the surface. Rutherford back-scattering is used to measure the $\mathrm{H}$ content. Raman spectroscopy has been used quite widely to characterize the bulk of the carbon films. Analysis of the ' $G$ ' and ' $D$ ' peaks can be used to determine the fractions of $s^{2}$ - and $\mathrm{sp}^{3}$-bonded carbon in the films. Finally, ESR has been used as a means of determining the concentrations of dangling bonds. These all reveal a quite complex material containing carbon atoms with a mixture of hybridizations and various types of partial oxidation and nitrogenation[60-64].

The surface of the amorphous carbon film on the hard disk is coated with an ultra-thin film of lubricant. Consideration of the nature of the problem reveals that there are enormous constraints on the types of materials that might be considered for use in such an application. The films of $<20 \AA$ thickness must survive for periods of up to five years in environments that reach operating temperatures of $\sim 80^{\circ} \mathrm{C}$ and cover a wide range of pressure and humidity. This requires that the lubricant be thermally and chemically stable, and that it have a very low rate of evaporation or, in other words, a very low vapor pressure. The most commonly used family of lubricants 
consists of the Fomblin ${ }^{\circledR}$ family, which are perfluoropolyalkyl ethers (PFPEs). They have the general structure

\section{$\mathrm{R}-\mathrm{CF}_{2} \mathrm{O}-\left(\mathrm{CF}_{3} \mathrm{CF}_{2} \mathrm{O}\right)_{n}-\left(\mathrm{CF}_{2} \mathrm{O}\right)_{m}-\mathrm{CF}_{2}-\mathrm{R}$}

These are high-molecular-weight polymers (1000 - $8000 \mathrm{amu})$ that are liquid and meet all the criteria listed above. There are a number of different end groups that can be used, including $\mathrm{R}=\mathrm{F}, \mathrm{CH}_{2} \mathrm{OH}$, and $\mathrm{CH}_{2} \mathrm{OCH}_{2} \mathrm{CH}(\mathrm{OH}) \mathrm{CH}_{2} \mathrm{OH}$, although by far the most commonly used has been Fomblin ${ }^{\circledR} \mathrm{Zdol}$, which is terminated by $-\mathrm{CH}_{2} \mathrm{OH}$ groups. After the disk surfaces have been sputter coated with magnetic media and then carbon overcoats, they are removed from vacuum and the lubricant is applied by dip-coating the disks into a solution of the lubricant in a fluorinated solvent[55,56,62].

Simply determining the lubricant thickness and uniformity on the surface of the disk is a challenging production-scale control problem. This is done most commonly by using ellipsometry measurements or FTIR in a reflection mode, to examine the absorption intensity from the $\mathrm{CF}_{2}$ stretch modes. Calibration of the coverage has been done using XPS[65-67]. The fact that the films on the carbon surface are roughly two monolayers in thickness means that their characteristics are truly determined by the properties of the adsorbed molecules and probably have little to do with the bulk properties of the fluid. Surface science is clearly needed in order to understand the tribological properties of these films - issues such as the nature of the bonding of the lubricant to the surface are important. Once coated on the surface, the lubricant appears to separate into two fractions: a 'bonded' fraction and a 'non-bonded' fraction. The evolution of the coverages of the two components and the evaporation of the lubricant with time has been measured using FTIR[67]. The nature of the 'bonded' species is not known, although it is clear that it is associated with the end groups of the molecule, since it does not occur for the $\mathrm{CF}_{3}$-terminated Fomblin ${ }^{\circledR}$ but does for the hydroxyl-terminated molecules. The non-bonded component is thought to be needed because it represents the fraction of the lubricant that is mobile on the surface. The mobility of the films has been studied in some detail using scanning microellipsometry. These studies have revealed that the hydroxyl-terminated Fomblin ${ }^{\circledR}$ family can form layered structures on the disk surface, while the $\mathrm{CF}_{3}$ terminated species do not[68]. Finally, the nature of the chemical interactions of Fomblin ${ }^{\circledR}$ lubricants with the a- $\mathrm{CH}_{\mathrm{x}}$ surface has been studied using model compounds and thermal desorption methods[60,69]. These have shown that the ether linkages interact with the carbon through a dative electron-donation mechanism, while the hydroxyl endgroups are hydrogen bonded to the surfaces. 
The fact that the lubricant films used for protection of data-storage media are so thin, mandates the need for a deep understanding of their surface chemistry. Surface analysis methods have already played an important role in this endeavour and will continue to be necessary as data storage technology places ever greater constraints and demands on the tribological performance of these systems.

\section{Vapor-Phase Lubrication}

Devices and applications requiring lubrication at extreme temperatures present tribological problems that cannot be solved using traditional, fluid-based lubricants. Although some of the perfluoropolyalkyl ethers used for hard-disk lubrication are, in fact, stable fluids at temperature as high as $\sim 400^{\circ} \mathrm{C}$, even this is insufficient for some applications. High-efficiency gas turbine engines can require lubrication at temperature in excess of $600^{\circ} \mathrm{C}$ and one can find applications needing lubrication at even higher extremes. One of the obvious solutions is the use of solid films, such as graphite or $\mathrm{MoS}_{2}$. However, under conditions of high or even moderate wear, these films must be periodically replaced. What is needed is a lubrication scheme based on thin solid films that can be replenished continuously and in situ.

One of the methods proposed and successfully tested for use in high-temperature gas turbine engines is known as vapor-phase lubrication (VPL)[70-72]. In this scheme, the lubricant is vaporized and added to a hot gas stream flowing through the engine. On contact with the hot surfaces of the engine components, it reacts to deposit a thin solid film, which lubricates and protects the engine surfaces from wear. This solid film is continuously worn away during engine operation, but is continuously replenished from the vapor phase. The compounds tested most commonly as vaporphase lubricants have been arylphosphates, such as tricresylphosphate (now referred to as TCP) shown below, and some alkylphosphates[73-75].

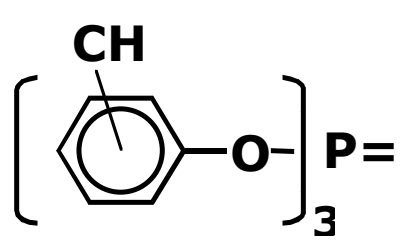

The mechanism by which these vapor-phase lubricants react on the surface to form lubricating films is undoubtedly quite complex and is certainly not well understood. It does, however, pose an interesting problem for surface science investigations. 
Effective vapor-phase lubrication films have been examined by scanning electron microscopy (SEM) and have structures consisting of micron-sized nodules[76-78]. These are observed to form on some metals such as steels but not on ceramics such as $\mathrm{SiC}$ or some Ni-based alloys. The films that showed poor lubricating characteristics had flaky structures that did not appear to adhere well to the substrate.

The lubricating thin films deposited by vapor-phase lubrication using TCP are thought to consist of polyphosphate glasses containing significant amounts of graphitic carbon[79,80]. A schematic representation of this thin film is illustrated in Figure 12. A number of surface-analytical measurements have been made in order to gain insight into the composition and structure of these films. Analysis of the film composition using XPS revealed the presence of phosphorus, carbon, and oxygen. The use of FTIR and Raman spectroscopy shows that the structure of these films is quite complex and includes bonding consistent with the presence of polyphosphate glass containing small graphitic particles. In addition, there is some evidence of the presence of P-O-C bonds. The thought is that the polyphosphate serves as a binder for the graphitic carbon[79,81]. Depth profiling using Auger spectroscopy to determine composition has shown that there is a significant amount of Fe present in the films[78].

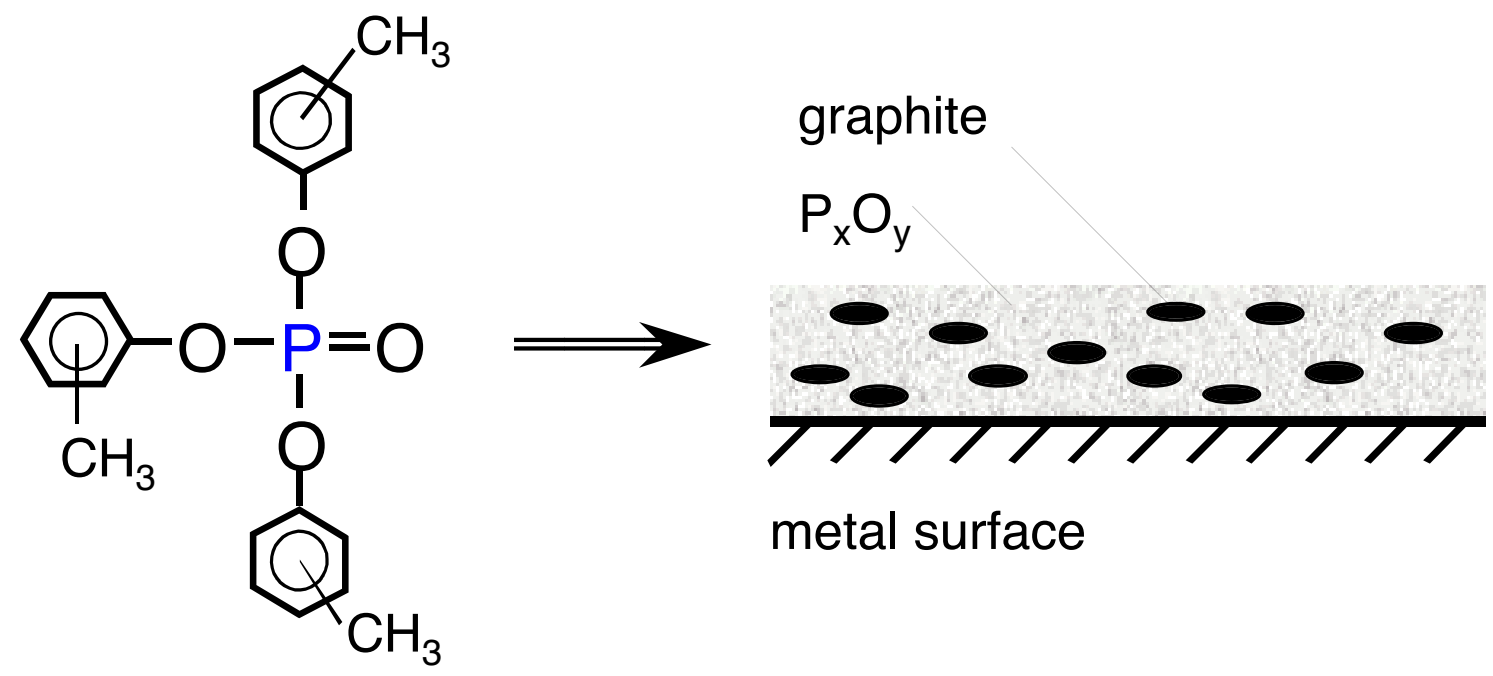

Figure 12. A schematic representation of the reaction of a vapour-phase lubricant (TCP) to form a thin film of polyphosphate glass with embedded graphite.

The formation of lubricating films by vapor deposition must be the result of a complex, multi-step reaction beginning with TCP and leading to the formation of both the polyphosphate film and embedded graphite. Besides what is known about the 
composition of the films themselves, there is evidence that the arylphosphates serve as better vapor phase lubricants than the alkylphosphates[74,75,82]. The root cause of this difference must lie in differences in the surface chemistry of these two classes of compounds. Arylphosphates $\left[(\mathrm{RO})_{3} \mathrm{P}=\mathrm{O}\right]$, such as TCP, are complex molecules and one can imagine a number of initial reaction steps or mechanisms which might initiate their decomposition into lubricating films of polyphosphate glasses. Initial reaction steps that appear to be likely include the cleavage of P-O bonds to form adsorbed aryloxy groups [RO-], or the cleavage of C-O bonds to form adsorbed aryl groups [R]. There have been several studies that try to shed light on this issue by using the model compound trimethylphosphite, $\left[\left(\mathrm{CH}_{3} \mathrm{O}\right)_{3} \mathrm{P}\right]$, the simplest organophosphorus compound containing these basic structural linkages[83-85]. These studies used temperature-programmed desorption (TPD) and XPS on the $\mathrm{Cu}(111), \mathrm{Ni}(111)$, and $\mathrm{Fe}(111)$ surfaces and all suggest that it is the $\mathrm{P}-\mathrm{O}$ bonds that are cleaved in the case of trimethylphosphite to produce adsorbed methoxy groups $\left[\mathrm{CH}_{3} \mathrm{O}-\right]$. Studies on Fe foils using TCP itself are a little bit harder to interpret but suggest that it is the $\mathrm{C}-\mathrm{O}$ bonds that dissociate to produce adsorbed toluyl groups $\left[\mathrm{CH}_{3}\left(\mathrm{C}_{4} \mathrm{H}_{4}\right)-\right][86,87]$. These investigations are still underway.

The nature of the ligand on the phosphates used for vapor-phase lubrication can have a substantial effect on their performance[74,75,82]. This can be understood in terms of the surface chemistry of the fragments that are left on the surface by scission of the $\mathrm{P}-\mathrm{O}$ or $\mathrm{C}-\mathrm{O}$ bonds in the phosphate. Alkyl ligands leave either alkyl or alkyoxy groups on the surface, as illustrated below with cyclohexanoxy and cyclohexyl groups. These are
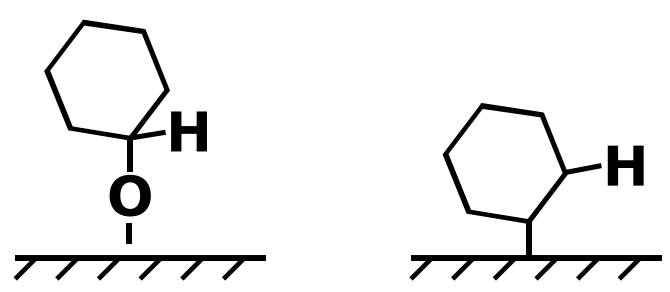

characterised by $\beta-\mathrm{CH}$ bonds, which tend to dissociate on most metal surfaces, releasing the adsorbed groups as either aldehydes or ketones in the case of alkoxy group, or olefins in the case of alkyl groups. These ligands can desorb from the surface quite readily and thus remove much of the surface carbon. Aryloxy and alkyloxy ligands have very different surface chemistry. The arlyoxy ligands dissociate from the phosphates by cleavage of either the $\mathrm{P}-\mathrm{O}$ or the $\mathrm{C}-\mathrm{O}$ bonds to produce either aryloxy or aryl groups on the surface. These cannot react by scission of $\beta-\mathrm{CH}$ bonds to generate 

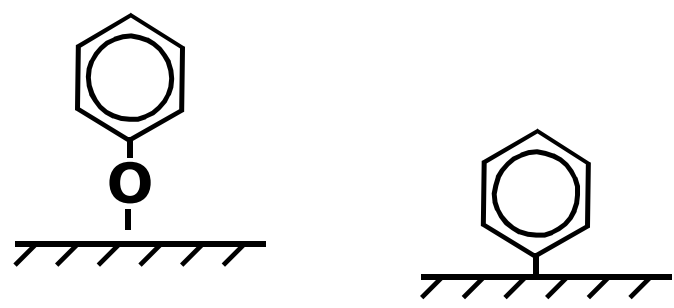

products that are easily desorbed into the gas phase. Instead, they react by complete dissociation to deposit large amounts of carbon onto the surface in the form of graphite. This chemistry has been illustrated using TPD to detect desorbing reaction products produced by scission of the $\beta-\mathrm{CH}$ bonds in the alkyl and alkyloxy groups, and AES to detect the carbon left on the surfaces due to decomposition of the aryl and aryloxy groups $[85,87,88]$. The fact that the aryloxy ligands decompose completely on the metal surfaces to deposit graphite suggests that this is an important component of the surface chemistry of vapor-phase lubrication and that the efficient deposition of graphite onto the surface or into the lubricating films is critical to the performance of the film as a solid lubricant.

\section{Tribology of Quasicrystals}

Quasicrystals constitute a class of alloys that have the unusual property of being ordered in these sense that their structures are deterministic but do not have periodicity. One of the most interesting consequences of this is that they have bulk symmetries such as five- and ten-fold rotation axes, which cannot be found in periodic lattices. They were first discovered, roughly 20 years ago, by Shechtman et al.[89]. Since then, many ternary and higher-order alloys have been found that have stable quasicrystalline structures.

The extraordinary structural properties of quasicrystals have motivated numerous measurements of materials properties that might be directly influenced by their quasicrystallinity. One such property that might lead to important commercial and technological applications of these materials is their tribological behavior. Interestingly, there have been a number of reports of apparently low friction measured on the quasicrystal surfaces[90-96]. From a tribological science perspective, however, the interesting question is whether such behavior is a direct consequence of quasicrystallinity.

There are several possible origins of the low frictional properties of quasicrystals. One, of course, is that because of their inherent lack of periodicity, quasicrystalline 
surfaces can never come into commensurate contact with one another or with any periodic surface. While the connection between commensurability and friction is far from being clearly resolved at the experimental level, there are several theoretical papers that predict such a connection[97,98]. Another obvious potential source of low friction during most friction measurement is the possible presence of thin adsorbed films. If the surfaces of quasicrystals are coated with thin films of contaminants that effectively serve as lubricants, the hardness of the quasicrystals results in low contact area and thus low friction. Hardness may be a result of the quasicrystalline structure and in this case serves as the link between friction and quasicrystallinity[90]. A similar idea is that thin oxide films on air-exposed quasicrystal surfaces serve as lubricants because they are only weakly adherent to the quasicrystal substrate and delaminate under shear[99]. Current work in the field of quasicrystal tribology is aimed at unraveling the competing theories and finding links between experimental tribological results and quasicrystallinity.

Making the connection between the macroscopic materials properties of quasicrystals and their atomic-level structure is a complicated problem. As always, there is a need for good experimental measurements of friction under well-defined conditions. This is always an issue in the discussion of tribological phenomena, since these are inherently surface-related properties and are extremely sensitive to the presence of surface contamination[99,100]. The second hurdle to any experimental test of the connection between quasicrystallinity and materials properties is that it is not possible to experimentally vary the relevant parameters in a truly independent manner. Many of the properties of such materials are not truly independent and thus cannot be varied independently. Changes in one parameter cause changes in others, to which they are physically coupled. Finally, in such problems one is faced with the fact that it is often impossible to change parameters continuously. For example, although the composition of an alloy may be varied continuously, its structure is dictated by a phase diagram that does not allow variation in a continuous manner. As a result of these numerous problems, it is difficult to find reliable measurements that allow one to make unambiguous statements about the role of quasicrystallinity in the determination of macroscopic materials properties. 
There have been a few studies of the frictional properties of quasicrystalline surfaces that have been performed under ultra-high vacuum conditions, which allow the controlled preparation and analysis of quasicrystal surfaces[101,102]. These have made use of the $\mathrm{Al}_{70} \mathrm{Pd}_{21} \mathrm{Mn}_{9}$ quasicrystal and $\mathrm{Al}_{48} \mathrm{Pd}_{42} \mathrm{Mn}_{10}$, an approximant of the quasicrystal. The latter has a composition that is similar to that of the quasicrystal, but has a $\mathrm{CsCl}$ structure that is periodic. The friction measurements were performed in a UHV surface-analysis chamber that allowed both controlled surface preparation and surface analysis before and after friction measurements. Figure 13 shows a LEED pattern of the $\mathrm{Al}_{70} \mathrm{Pd}_{21} \mathrm{Mn}_{9}$ quasicrystal taken from a five-fold symmetric plane.
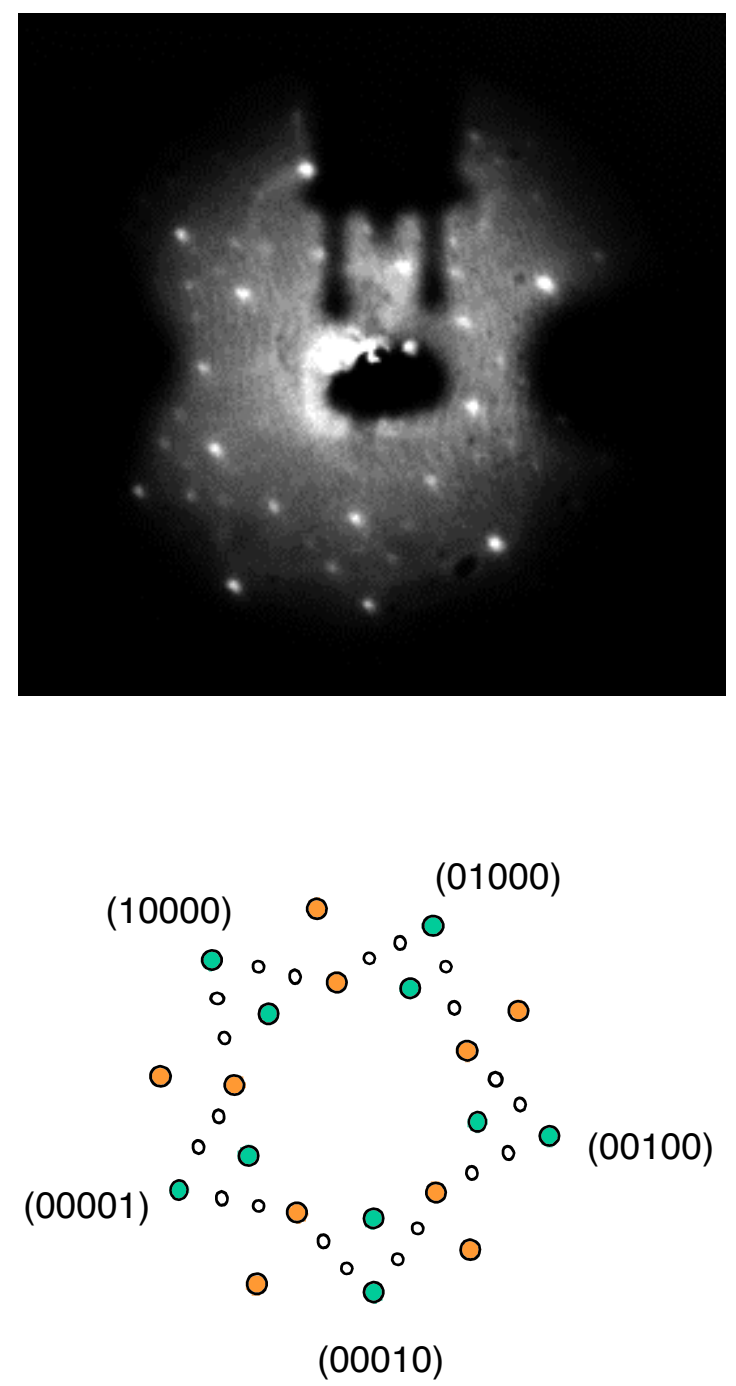

This surface was sputtered and annealed to generate a truly clean surface for friction measurements. 
Figure 13. A low-energy electron diffraction pattern of the truly clean $A l_{70} P d_{21} M n_{9}$ quasicrystal on its five-fold symmetric surface. Two of these truly clean surfaces were used for subsequent friction measurements in vacuum.

Prior to cleaning in vacuum, the surfaces of the $\mathrm{Al}_{70} \mathrm{Pd}_{21} \mathrm{Mn}_{9}$ quasicrystals were analyzed using AES and shown to be contaminated by a layer of carbon, sulfur, chlorine, and oxygen. The friction coefficient between these two surfaces was $\mu_{\mathrm{s}}=$ $0.11 \pm 0.02$. After cleaning in vacuum the friction coefficient rose to $\mu_{s}=0.60 \pm 0.08$. Clearly the friction of these surfaces is heavily influenced by the presence of air-borne contaminants and without making measurements in vacuum it is not possible to probe the frictional properties intrinsic to the quasicrystal itself.

The use of UHV methods allows the preparation of truly clean surfaces for friction measurements. However, it also allows the controlled preparation of adsorbed layers on such surfaces. The $\mathrm{Al}_{70} \mathrm{Pd}_{21} \mathrm{Mn}_{9}$ quasicrystal surface was modified by controlled exposures to $\mathrm{O}_{2}$ and to $\mathrm{H}_{2} \mathrm{O}$ in order to grow thin oxide films. AES shows that exposure to $\mathrm{O}_{2}$ results in the formation of a thin film of aluminum oxide that passivates the surface against further oxidation. This is similar to the oxidation of the surface of aluminum itself $[101,102]$. These films have an influence on the frictional properties of the surface. This is revealed below in figure 14, which shows the friction coefficient measured as a function of the degree of oxidation by both $\mathrm{O}_{2}$ and $\mathrm{H}_{2} \mathrm{O}$. It is quite apparent that the presence of oxide films will reduce the friction between the quasicrystal surfaces. 


\section{Quasicrystal and Approximant Friction versus Oxidation}

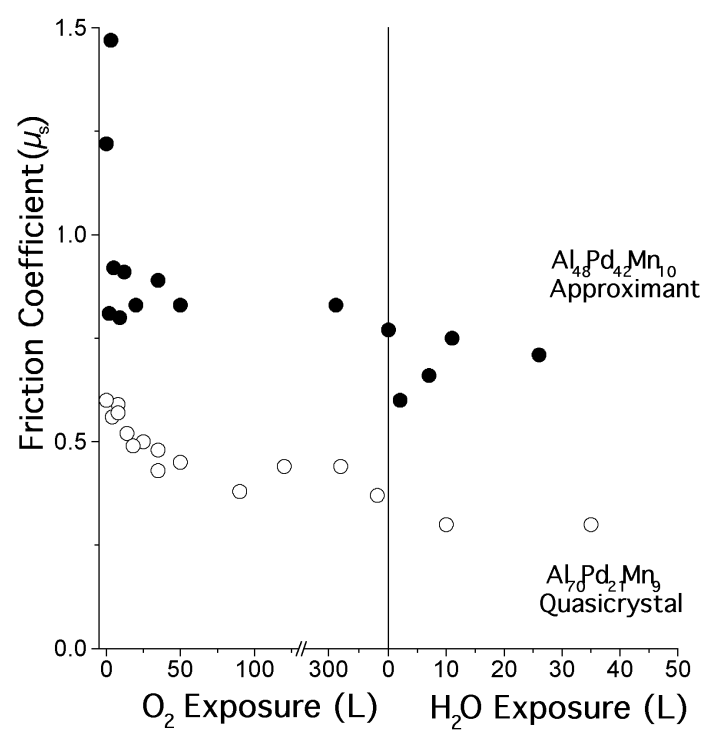

Figure 14. Friction coefficient between two $A l_{70} P d_{21} M n_{9}$ quasicrystal surfaces and two $\mathrm{Al}_{48} \mathrm{Pd}_{42} \mathrm{Mn}_{10}$ approximant surfaces as a function of surface exposure to $\mathrm{O}_{2}$ and $\mathrm{H}_{2} \mathrm{O}$. The friction clearly drops as a function of the level of oxidation. It is also apparent that the friction between the approximant surfaces is roughly twice that of the quasicrystals at all levels of oxidation.

In order to test the importance of the bulk crystal structure and quasicrystallinity on the friction of these alloys, similar measurements have been performed with the $\mathrm{Al}_{48} \mathrm{Pd}_{42} \mathrm{Mn}_{10}$ approximant phase. As with the quasicrystal phase, the presence of airborne contaminants on the surface of the approximant phase has a significant effect on friction. The interesting thing is that once these contaminants have been removed from the surface and the surface is clean, as determined by AES, the friction is roughly twice that of the quasicrystal. Furthermore, figure 14 reveals that the friction remains higher than that of the quasicrystal at all levels of oxidation.

The results of the comparison between the frictional properties of the quasicrystals and their approximants clearly show that there are differences between them. Unfortunately, this is still insufficient to prove that the quasicrystalline structure is the determining factor. Nonetheless this is a very interesting result and one that could not have been obtained without the combined use of surface analytical approaches and tribological measurements. 


\section{Conclusions}

In pursuit of our original objective - a survey of surface chemistry in tribology - we have illustrated a number of tribological problems and technologies in which surface chemistry is a critical component. As technologies push the need for tribological knowledge to new frontiers and demand solutions to tribology problems in new environments, such as the human body or the vacuum of space, a greater and deeper understanding of the influences of surface chemistry on tribology is needed. As our examples illustrate, the types of chemistry that are implicated in tribological phenomena are broad and varied. It is probably fair to say that at this time there is no single theory or concept that broadly describe the role of molecules in reducing friction at interfaces. Much of the understanding that we have gained over the past century has been specific to the problems at hand. In fact what is needed to successfully approach the study of tribological surface chemistry and to solve real tribological problems is a broad understanding of organic chemistry, solid-state chemistry, materials chemistry and, of course, the mechanical aspects of tribology and contact mechanisms.

Broadly speaking, however, one can make a few general statements about the role of surface science as an approach to solving tribological problems. There is no doubt that the tools developed by physicists and chemists in the field of surface science have had a major impact on our understanding of tribology. Electron microscopy, Auger spectroscopy, and the many other tools of the trade have provided tribologists with a molecular or atomic scale understanding of the world of the solid-solid interface. However, in addition, the field of surface science has provided the tools and the means for preparing highly controlled and highly characterized interfaces between solids. These are clearly needed in order to separate the many variables that can influence friction and the role of lubricants at interfaces. While the complexities of these problems are undisputed, inspiration, creativity and hard work, both in the laboratory and by theoreticians, has pushed forward our understanding of lubrication and will continue to do so for the foreseeable future. 


\section{References}

1 Hutchings, I.M. Tribology - Friction and Wear of Engineering Materials, 1992. (Arnold, London)

2 Spikes, H.A., Boundary Lubrication and Boundary Films. In D. Dowson et al. (Eds.), Thin Films in Tribology,, pp. 331-346 Elsevier Science Publishers B.V., Amsterdam, 1993.

3 Stanton, T.E. Friction,, 1923. (Longmans, Green \& Co., London)

4 Deeley, R.M. Oiliness and lubrication. Discussion on lubrication. Proc. Phys. Soc., 1919, 32, 1s-11s.

$5 \quad$ Hardy, W.B. and Bircumshaw, I. Boundary lubrication-plane surfaces and the limitations of Amontons' Law. Proc. R. Soc. London, A, 1925, 108, 1-27.

6 Allen, C.M. and Drauglis, E. Boundary layer lubrication: monolayer or multilayer. Wear, 1969, 14, 363-384.

7 Bowden, F.P. and Tabor, D. Friction and Lubrication of Solids, 1950. (Oxford University Press, Oxford, UK)

8 Williams, J.A. Engineering Tribology,, 1994. (Oxford University Press, Oxford, UK)

9 Studt, P. The influence of the structure of isometric octadecanols on their adsorption from solution on iron and their lubricating properties. Wear, 1981, 70, 329-334.

10 Stachowiak, G.W. and Batchelor, A.W. Engineering Tribology,, 1993. (Elsevier, Amsterdam)

11 Fischer, D.A., Hu, Z.S. and Hsu, S.M. Molecular orientation and bonding of monolayer stearic acid on a copper surace prepared in air. Trib. Lett., 1997, 3, 41-46.

12 Ratoi, M., Anghel, V., Bovington, C.H. and Spikes, H.A. Mechanisms of oiliness additives. Trib. Int., 2000, 33, 241-247.

13 Spikes, H.A. Direct observation of boundary layers. Langmuir, 1996, 12, 4567-4573.

14 Anghel, V., Bovington, C.H. and Spikes, H.A. Thick film formation by friction modifier additives. Lubr. Sci., 1999, 11, 313-335.

15 Ratoi, M., Bovington, C.H. and Spikes, H.A. Mechanism of metal carboxylate friction modifier additive behavior., International Tribology Conference, Nagasaki, 2000.

16 Çavdar, B. and Ludema, K.C. Dynamics of dual film formation in boundary lubrication of steels. Part I functional nature and mechanical properties. Wear, 1991, 148, 305-327.

17 Çavdar, B. and Ludema, K.C. Dynamics of Dual Film Formation in Boundary Lubrication of Steels, Part 2: Chemical Analyses. Wear, 1991, 148, 329-346. 
18 Çavdar, B. and Ludema, K.C. Dynamics of Dual Film Formation in Boundary Lubrication of Steels, Part 3: Real Time Monitoring with Ellipsometry. Wear, 1991, 347-361.

19 Hsu, S.M. Boundary Lubrication: current understanding. Trib. Lett., 1997, 3, $1-11$.

20 Israelachvili, J.N., McGuiggan, P.M. and Homola, A.M. Dynamic properties of molecularly thin liquid films. Science (Washington, D. C., 1883), 1988, 240, 189-191.

21 Granick, S. Motions and relaxations of confined liquids. Science (Washington, D. C., 1883-), 1991, 253, 1374-1379.

22 Heuberger, M., Zäch, M. and Spencer, N.D. When is a fluid not a fluid? Science (Washington, D. C., 1883-), 2001, in Press.

23 Persson, B.N.J. Sliding Friction, Physical Principles and Applications, 1998. (Springer-Verlag, Berlin Heidelberg)

24 Widmer, M.R., Heuberger, M. and Spencer, N.D. Influence of Polymer Surface Chemistry on Frictional Properties Under Protein-Lubrication Conditions. Trib. Lett., 2001, 10, 111-116.

25 Habeeb, J.J. and Stover, W.H. The Role of Hydroperoxides in Engine Oil and the Effect of Zinc Dialkylthiophosphates. ASLE Transactions, 1987, 30, 419-426.

26 Roper, G.W. and Bell, J.C., Review and evaluation of lubricated wear in simulated valve train contact conditions SAE 952473., Recent Snapshots and Insights into Lubricant Tribology SP-1116,, pp. 67-83 Society of Automotive Engineers, Warrendale, PA, 1995.

27 Bec, S., Tonck, A., Georges, J.M., Coy, R.C., Bell, J.C. and Roper, G.W. Relationship between mechanical properties and structures of zinc dithiophosphate anti-wear films. Proc. R. Soc. London, A, 1999, 455, 41814203.

28 Debies, T.P. and Johnson, W.G. Surface chemistry of some antiwear additives as determined by electron spectroscopy. ASLE Transactions, 1980, 23, 289-297.

29 Jahanmir, S. Wear reduction and surface layer formation by a ZDDP additive. J. Trib., 1987, 109, 577-586.

$30 \quad$ Kasrai, M., Fuller, M., Scaini, M., Yin, Z., Brunner, R.W., Bancroft, G.M., Fleet, M.E., Fyfe, K. and Tan, K.H., Study of tribochemical film formation using x-ray absorption and photoelectron spectroscopies. In D. Dowson et al. (Eds.), Proc. 21st Leeds/Lyon Symp., Lubricants and Lubrication,, pp. 659-669 Elsevier Science B:V:, 1995.

31 Rhodes, K.L. and Stair, P.C. The effect of ZDP's on the surface chemistry of hydrocarbon films on oxidized iron substrates. Tribol. Trans., 1993, 36, 27-34. 
32 Yin, Z., Kasrai, M., Bancroft, G.M., Laycock, K.F. and Tan, K.H. Chemical Characterization of antwear Films generated on Steel by Zinc Dialkyl Dithiophosphate using X-ray Adsorption Spectroscopy. Trib. Int., 1993, 26, 383-388.

33 Yin, Z., Kasrai, M., Fuller, M., Bancroft, G.M., Fyfe, K., Yamaguchi, E.S., Ryason, P.R., Willermet, P.A. and Tan, K.H. Application of soft Xray absorption spectroscopy in chemical characterization of antiwear films generated by ZDDP: Part I-The effect of physical parameters. Wear, 1997, 202, 172-191.

34 Bancroft, G.M., Kasrai, M., Fuller, M. and Yin, Z. Mechanisms of Tribological Film Formation: Stability of tribo-thermally-generated ZDDP Films. Tribology Letters, 1997, 3, 47-51.

35 Suominen Fuller, M.L., Kasrai, M., Bancroft, G.M., Fyfe, K. and Tan, K.H. Solution decomposition of zinc dialkyl dithiophosphate and its effect on antiwear and thermal film formation studied by x-ray absorption spectroscopy. Trib. Int., 1998, 31, 627-664.

36 Ferrari, E.S., Roberts, K.J., Sansone, M. and Adams, D. A multi-edge Xray absorption spectroscopy study of the reactivity of zinc di-alkyl-dithiophosphates anti-wear additives 2. In situ studies of steel/oil interfaces. Wear, 1999, 236, 259-275.

37 Canning, G.W., Suominen Fuller, M.L., Bancroft, G.M., Kasrai, M., Cutler, J.N., De Stasio, G. and Gilbert, B. Spectromicroscopy of tribological films from engine oil additives. Part I. Films from ZDDP's. Trib. Lett., 1999, 6, 159-169.

38 Suominen Fuller, M.L., Rodriguez Fernandez, L., Massoumi, G.R., Lennard, W.N., Kasrai, M. and Bancroft, G.M. The use of X-ray absorption spectroscopy for monitoring the thickness of antiwear films from ZDDP. Trib. Lett., 2000, 8, 187-192.

39 Varlot, K., Kasrai, M., Martin, J.M., Vacher, B., Bancroft, G.M., Yamaguchi, E.S. and Ryason, P.R. Antiwear film formation of neutral and basic ZDDP: influence of the reaction temperatue and of the concentration. Trib. Lett., 2000, 8, 9-16.

40 Willermet, P.A., Carter, R.O. and Boulos, E.N. Lubricant-derived tribochemical Films- An Infra-red Spectroscopy Study. Trib. Int., 1992, 25.

41 Bell, J.C., Delargy, K.M. and Seeney, A.M., The Removal of Substrate Material through thick zinc dithiophosphate Anti-Wear Films. In D. Dowson et al. (Eds.), Proc. 18th Leeds/Lyon Symp., Wear Particles: from the cradle to the grave,, pp. 387-396 Elsevier Science Publishers B.V., 1992.

42 Pidduck, A.J. and Smith, G.C. Scanning probe microscopy of automotive anti-wear films. Wear, 1997, 212, 254-264. 
43 Graham, J.F., McCague, C. and Norton, P.R. Topography and nanomechanical properties of tribochemical films derived from zinc dialkyl and diaryl dithiophosphates. Trib. Lett., 1999, 6, 149-157.

44 Georges, J.M., Tonck, A., Poletti, S., Yamaguchi, E.S. and Ryason, P.R. Film thickness and mechanical properties of adsorbed neutral and basic zinc diisobutyl dithiophosphates. Tribol. Trans., 1998, 41, 543-553.

45 Sheasby, J.S. and Nisenholz Rafael, Z. Antiwear characteristics of a commercial secondary ZDDP additive. Tribol. Trans., 1993, 36, 399-404.

46 Sheasby, J.S. and Caughlin, T.A., The direct observation of the anti-wear action of ZDDP. In D. Dowson et al. (Eds.), Proc. 21st Leeds/Lyon Symp., Lubricants and Lubrication,, pp. 399-408 Elsevier Science B.V., 1995.

47 Gunsel, S., Spikes, H.A. and Aderin, M. In-Situ measurement of ZDDP films in concentrated contacts. Tribol. Trans., 1993, 36, 276-282.

48 Armstrong, D.R., Ferrari, E.S., Roberts, K.J. and Adams, D. An examination of the reactivity of zinc di-alkyl-di-thiophosphate in relation to its use as an anti-wear and anti-corrosion additive in lubricating oils. Wear, 1998, 217, 276-287.

49 Bovington, C.H. and Dacre, B. The adsorption and reaction of decomposition products of zinc di-isopropyldithiophosphate on steel. ASLE Transactions, 1984, 27, 252-258.

50 Martin, J.M. Antiwear mechanisms of zinc dithiophosphate: a chemical hardness approach. Trib. Lett., 1999, 6, 1-8.

51 Coy, R.C. and Jones, R.B. The thermal degradation and EP performance of zinc dialkyldithiophosphate additives in white oil. ASLE Transactions, 1980, 24, 77-90.

52 Jones, R.B. and Coy, R.C. The chemistry and thermal degradation of zinc dialkyldithiophosphate additives. ASLE Transactions, 1981, 24, 91-97.

53 Ho, T.-L. The hard soft acids bases (HSAB) principle and organic chemistry. Chem. Rev., 1975, 75, 1.

54 Taylor, L., Dratva, A. and Spikes, H.A. Friction and wear behavior of zinc dialkyldithiophosphate additive. Tribol. Trans., 2000, 43, 469-479.

55 Gellman, A.J. Lubricants and Overcoats for Magnetic Storage Media. Current Opinion in Colloid and Interface Science, 1998, 3, 368-372.

56 Mate, C.M. Picking the best lubricant for contact recording. Data Storage, 1997, 45-48.

57 Mate, C.M. and Homola, A.M. (Eds.), Micro/Nanotribology and its Aplications, Molecular Tribology of Disk Drives, Kluwer Academic Publ, Netherlands, 1997, 647-661 pp.

58 Kryder, H.M. Ultrahigh-density recording technologies. Mat. Res. Soc. Bull., 1996, 21, 17-22. 
59 Thompson, D.A. The role of perpendicular recording in the future of hard disk storage. J. Magnetics. Soc. Jap., 1997, 21, 9-15.

60 Shukla, N. and Gellman, A.J. Interaction of Alcohols with a-CHx Films. $J$. Vac. Sci. Technol., 2000, 18, 2319-2326.

61 Kobayashi, A., Yoshitomi, D., Yoshihara, O., Imayoshi, T., Kinbara, A., Fumoto, T. and Ueno, M. Carbon films for the protection of magnetic recording media. Surface and Coating Technology, 1995, 72, 152-156.

62 Cho, N.-H., Krishnan, K.M., Veirs, D.K., Rubin, M.D., Hopper, C.B. and Bhushan, B. Chemical structure and physical properties of diamond-like amorphous carbon films prepared by magnetron sputtering. J. Mater. Sci., 1995, 5, 2543-2554.

63 Tsai, H. and Bogy, D. Critical Review: Characterization of diamond-like carbon films and their application as overcoats on thin-film media for magnetic recording. J. Vac. Sci. Technol. A, 1987, 5, 3287-3312.

64 Yanagisawa, M. Adsorption of perfluoropolyethers on carbon surfaces. Trib. and Mech. of Magnetic Storage System, 1994, 9, 36.

65 Toney, M.F., Mate, C.M. and Pocker, D.J. Calibrating ESCA and ellipsometry measurements of perfluoropolyether lubricant thickness. IEEE Trans. Magn., 1998, 34, 1774.

66 Gao, C. and Dai, P. Molecular orientation of PFPE lubricant films and its quantification. IEEE Trans. Magn., 1997, 33, 3118-3120.

67 Tyndall, G.W. and Waltman, R.J. Thermodynamics of confined perfluoropolyether films on amorphous carbon surfaces determined from the time-dependent evaporation kinetics. J. Phys. Chem. B, 2000, 104, 7085-7095.

68 Ma, X., Gui, J., Smoliar, L., Grannen, K., Marchon, B., Bauer, C.L. and Jhon, M.S. Complex terraced spreading of perfluoropolyalkylether films on carbon surfaces. Phys. Rev. E., 1999, 59, 722-726.

69 Cornaglia, L. and Gellman, A.J. Fluoroether Bonding to Carbon Overcoats. J. Vac. Sci. Technol. A, 1997, 15, 2755-2765.

70 Van Treuren, K.W., Barlow, D.N., Heiser, W.H., Wagner, M.J. and Forster, N.H. Investigation of Vapor-phase Lubrication in a Gas Turbine Engine. J. of Eng. for Gas Turbines and Power, 1998, 120, 257.

71 Rao, A.M.N. Vapor-Phase Lubrication: Application-Oriented Development. Lubr. Eng., 1996, 52, 856-862.

72 Placek, D.G. and Freiheit, T. Progress in Vapor Phase Lubrication Technology. J. of Eng. for Gas Turbines and Power, 1993, 115, 700-705.

73 Forster, N.H. and Trivedi, H.K. Rolling Contact Testing of Vapor Phase Lubricants - Part II: System Performance Evaluation. Trib. Trans., 1997, 40, 493-499.

74 Forster, N.H. and Trivedi, H.K. Rolling Contact Testing of Vapor Phase Lubricants - Part I: Material Evaluation. Trib. Trans., 1997, 40, 421-428. 
75 Groeneweg, M., Hakim, N., Barber, G.C. and Klaus, E. Vapor Delivered Lubrication of Diesel Engines - Cylinder Kit Rig Simulation. Lubr. Eng., 1991, 47, 1035-1039.

76 Makki, J. and Graham, E. Formation of Solid Films from the Vapor Phase on High Temperature Surfaces. Lubr. Eng., 1990, March, 199-206.

77 Makki, J.F. and Graham, E.E. Vapor Phase Deposition on High Temperature Surfaces. Trib. Trans., 1990, 33, 595-603.

78 Hanyaloglu, B.F., Graham, E.E., Oreskovic, T. and Hajj, C.G. Vapor Phase Lubrication of High Temperature Alloys. Lubr. Eng., 1994, 51, 503508.

79 Forster, N.H. Rolling Contact Testing of Vapor Phase Lubricants - Part III: Surface Analysis. Trib. Trans., 1999, 42, 1-9.

80 Hanyaloglu, B. and Graham, E.E. Vapor Phase Lubrication of Ceramics. Lubr. Eng., 1994, 50, 814.

81 Morales, W., Hanyaloglu, B.F., Graham, E.E. Infrared Analysis of Vapor Phase Deposited Tricresyl Phosphate (TCP). NASA, 1994, TM106423.

82 Forster, N.H. personal communication., 2000.

83 Holbert, A.W., Batteas, J.D., Wong-Foy, A., Rufael, T.S. and Friend, C.M. Passivation of $\mathrm{Fe}(110)$ via Phosphorus Deposition: The Reactions of Trimethylphosphite. Surf. Sci., 1998, 401, L437.

84 Ren, D., Zhou, G. and Gellman, A.J. The Decomposition Mechanism of Trimethylphosphite on Ni(111). Surf. Sci., 2001, 475, 61-72.

85 Ren, D. and Gellman, A.J. The Carbon Deposition Mechanism in Vapor Phase Lubrication. Trib. Trans., 2000, 43, 480-488.

86 Wheeler, D.R. and Fuat, O.D. The adsorption and thermal-decomposition of tricresylphosphate (TCP) on iron and gold. Appl. of Surf. Sci., 1984, 18, 106.

87 Sung, D. and Gellman, A.J. The surface chemistry of alkyl and arylphosphates on $\mathrm{Fe}$ foil. in preparation.

88 Ren, D. and Gellman, A.J. Reaction mechanisms in organophosphate vapor phase lubrication of metal surfaces. Trib. Int., 2001.

89 Shechtman, D., Blech, I., Gratias, D. and Cahn, J.W. Metallic phase with long-range orientational order and no translational symmetry. Phys. Rev. Lett., 1984, 53, 1951.

90 Kang, S.S., Dubois, J.M. and von Stebut, J. Tribological properteis of quasicrystalline coatings. J. Mater. Res., 1993, 8, 2471-2481.

91 Dubois, J.M., Kang, S.S. and Perrot, A. Towards apllication of quasicrystals. Mater. Sci. and Eng., 1994, A179/A180.

92 Wittmann, R., Urban, K., Schandl, M. and Hornbogen, E. Mechanical properties of single quasi-crystalline AlCuCoSi. J. Mater. Res., 1991, 6, 1165 1168. 
93 Dubois, J.M., Kang, S.S. and von Stebut, J. Quasi-crystalline low-friction coatings. J. Mat. Sci. Lett., 1991, 10, 537-541.

94 von Stebut, J., Soro, J.M., Plaindoux, P. and Dubois, J.M. (Eds.), New Horizons in Quasicrystals Research and Applications, Friction behavior of pure quasicrystalline materials, World Scientific Publishing, Singapore, 1997, 248-255 pp.

95 Gavatz, M., Rouxel, D., Pigeat, P., Weber, B. and Dubois, J.M. Surface oxidation of the $\mathrm{Al}_{62} \mathrm{Cu}_{25.5} \mathrm{Fe}_{12.5}$ icosahedral quasicrystal. Phil. Mag. A, 2000, 80, 2083.

96 Pinhero, P.J., Anderegg, J.W., Sordelet, D.J., Besser, M.F. and Thiel, P.A. Surface oxidation of Al-Cu-Fe alloys: a comparison of quasicrystalline and crystalline phases. Phil. Mag. B, 1999, 79, 91-110.

97 He, G., Muser, M.H. and Robbins, M.O. Adsorbed layers and the origin of static friction. Science, 1999, 284, 1650.

98 Sokoloff, J.B. Theory of energy dissipation in sliding crystal surfaces. Physical Review B, 1990, 42, 760-765.

99 Gellman, A.J. Lubrication by Molecular Monolayers at Ni-Ni Interfaces. $J$. Vac. Sci. Technol. A, 1992, 10, 180.

100 McFadden, C.F. and Gellman, A.J. Ultra-high Vacuum Boundary Lubrication of the $\mathrm{Cu}-\mathrm{Cu}$ Interface by 2,2,2-Trifluoroethanol. Langmur, 1995, 11, 273.

101 Ko, J.S., Gellman, A.J., Jenks, C., Lograsso, T. and Thiel, P.A. Friction Between Single Grain $\mathrm{Al}_{70} \mathrm{Pd}_{21} \mathrm{Mn}_{9}$ Quasicrystal Surfaces. Suf. Sci., 1999, 423, 243-255.

102 Mancinelli, C., Ko, J.S., Jenks, C.J., Thiel, P.A., Ross, A.R., Lograsso, T.A. and Gellman, A.J. Comparative Study of the Tribological and Oxidative Properties of AlPdMn Quasicrystals and Their Cubic Approximants., Mater. res. Soc., MRS Publ., Boston, 2000, pp. in press. 